ARTICLE

DOI: $10.1038 / s 41467-018-04127-6$

\title{
Depletion of Nsd2-mediated histone H3K36 methylation impairs adipose tissue development and function
}

Lenan Zhuang (1) 1, Younghoon Jang (1) 1, Young-Kwon Park', Ji-Eun Lee (1) ${ }^{1}$, Shalini Jain², Eugene Froimchuk , Aaron Broun ${ }^{1}$, Chengyu Liu ${ }^{3}$, Oksana Gavrilova ${ }^{2} \&$ Kai Ge ${ }^{1}{ }^{1}$

The epigenetic mechanisms regulating adipose tissue development and function are poorly understood. In this study, we show that depletion of histone H3K36 methylation by $\mathrm{H} 3.3 \mathrm{~K} 36 \mathrm{M}$ in preadipocytes inhibits adipogenesis by increasing H3K27me3 to prevent the induction of $\mathrm{C} / \mathrm{EBP} \alpha$ and other targets of the master adipogenic transcription factor peroxisome proliferator-activated receptor- $\gamma$ (PPAR $\gamma$ ). Depleting H3K36 methyltransferase Nsd2, but not Nsd1 or Setd2, phenocopies the effects of H3.3K36M on adipogenesis and PPAR $\gamma$ target expression. Consistently, expression of H3.3K36M in progenitor cells impairs brown adipose tissue (BAT) and muscle development in mice. In contrast, depletion of histone H3K36 methylation by H3.3K36M in adipocytes in vivo does not affect adipose tissue weight, but leads to profound whitening of BAT and insulin resistance in white adipose tissue (WAT). These mice are resistant to high fat diet-induced WAT expansion and show severe lipodystrophy. Together, these results suggest a critical role of Nsd2-mediated H3K36 methylation in adipose tissue development and function.

\footnotetext{
${ }^{1}$ Adipocyte Biology and Gene Regulation Section, LERB, National Institute of Diabetes and Digestive and Kidney Diseases, NIH, Bethesda, MD 20892, USA ${ }^{2}$ Mouse Metabolism Core Laboratory, National Institute of Diabetes, Digestive and Kidney Diseases, NIH, Bethesda, MD 20892, USA. ${ }^{3}$ Transgenic Core, National Heart, Lung, and Blood Institute, NIH, Bethesda, MD 20892, USA. These authors contributed equally: Younghoon Jang, Young-Kwon Park. Correspondence and requests for materials should be addressed to K.G. (email: kai.ge@nih.gov)
} 
A dipose tissue plays a critical role in regulating energy balance and glucose homeostasis ${ }^{1}$. In mammals, there are two types of adipose tissue: white and brown. White adipose tissue (WAT) is composed of white adipocytes containing a single, large lipid droplet. WAT is mainly located in the subcutaneous and abdominal areas of the body. WAT stores excess energy in the form of triglyceride. In addition, WAT regulates energy balance through the synthesis and secretion of adipokines such as leptin, adiponectin, resistin, and angiotensinogen (Agt) ${ }^{1}$. Brown adipose tissue (BAT) is composed of brown adipocytes enriched with numerous mitochondria and is mainly located in the interscapular region in rodents ${ }^{2}$. In contrast to WAT, BAT is specialized in expending energy to generate heat. The thermogenic function of BAT is largely due to the expression of uncoupling protein-1 (Ucp1), a BAT selectively expressed mitochondrial protein ${ }^{3}$. In adipose tissues, the sympathetic nervous system regulates thermogenesis and lipolysis through the $\beta 3$ adrenergic signaling pathway ${ }^{4}$.

Development of adipose tissue (adipogenesis) is under the control (Ctrl) of transcriptional and epigenetic mechanisms. Adipogenic transcription factors have been studied extensively ${ }^{5,6}$. Peroxisome proliferator-activated receptor- $\gamma(\operatorname{PPAR} \gamma)$, a nuclear receptor, is the master regulator in both white and brown adipogenesis ${ }^{7}$. Several CCAAT/enhancer-binding protein (C/EBP) family members, especially $\mathrm{C} / \mathrm{EBP} \alpha$, activate and maintain the expression of PPAR $\gamma$. C/EBP $\alpha$ and PPAR $\gamma$ promote each other's expression and cooperate to activate the expression of thousands of genes critical for the phenotypic conversion of preadipocytes to adipocytes ${ }^{7}$. Methylation on histone $\mathrm{H} 3$ lysine 4 (H3K4), $\mathrm{H} 3 \mathrm{~K}$, and $\mathrm{H} 3 \mathrm{~K} 27$ have also been implicated in regulating adipogenesis ${ }^{8-13}$. Histone methylation is also implicated in regulating adipocyte functions. For example, BAT-selective ablation of Lsd1, an $\mathrm{H} 3 \mathrm{~K} 4$ and $\mathrm{H} 3 \mathrm{~K} 9$ demethylase, leads to the down-regulation of BAT-selective genes but up-regulation of WAT-selective genes, resulting in lipid accumulation and whitening of $\mathrm{BAT}^{14}$. However, the role of $\mathrm{H} 3 \mathrm{~K} 36$ methylation in adipogenesis and adipocyte function has remained unclear.

H3K36 methylation has been shown to associate with active transcription. Multiple H3K36 methyltransferases have been described ${ }^{15}$. Setd2 is an H3K36 tri-methyltransferase responsible for the majority of H3K36me3 in cells ${ }^{16}$. Nsd1 and Nsd2 show specific mono-methyltransferase and di-methyltransferase activity on H3K36, generating H3K36me1 and H3K36me2 ${ }^{17,18}$. Depletion of Nsd2 in cells decreases global H3K36me2 but does not affect H3K36me $3^{17,19}$. Nsd2-depleted cells show increased levels of global $\mathrm{H} 3 \mathrm{~K} 27 \mathrm{me} 3^{19}$, a finding consistent with in vitro data that H3K36 methylation antagonizes PRC2-mediated H3K27 methylation ${ }^{20}$. The increased H3K27me3 results in the repression of gene expression ${ }^{19}$. Thus, the dynamics of H3K36me2 could change the chromatin landscape of H3K27me3, thereby altering transcriptional programs.

Recently, genetic mutation of lysine 36 to methionine (K36M) of histone H3.3 was reported in chondroblastoma patients ${ }^{21}$. Ectopic expression of K4M, K9M, K27M, and K36M mutants of H3.3 specifically deplete endogenous $\mathrm{H} 3 \mathrm{~K} 4, \mathrm{H} 3 \mathrm{~K} 9, \mathrm{H} 3 \mathrm{~K} 27$, and H3K36 methylation, respectively ${ }^{22,23}$. In this study, we use K36M mutant of histone $\mathrm{H} 3$ as a tool to clarify the role of histone K36 methylation in adipose tissue development and function. We found that the expression of $\mathrm{H} 3.3 \mathrm{~K} 36 \mathrm{M}$ in progenitor cells prevents adipogenesis in cell culture, and adipose tissue and muscle development in mice. On the other hand, expression of H3.3K36M in adipocytes has little effects on adipogenesis, but reprograms adipocyte gene expression profile and impairs adipose tissue functions. Mechanistically, H3.3K36M inhibits adipogenesis by blocking PPAR $\gamma$ target gene expression. Depletion of the major H3K36 methyltransferase Nsd2, but not Nsd1 or Setd2, phenocopies the inhibitory effects of $\mathrm{H} 3.3 \mathrm{~K} 36 \mathrm{M}$ on adipogenesis and PPAR $\gamma$ target gene expression.

\section{Results}

H3.3K36M increases H3K27me3 to inhibit adipogenesis. To understand the role of histone H3K36 methylation in adipogenesis, we used retroviruses to stably express wild-type (WT) or K36M mutant of histone $\mathrm{H} 3.3$ in brown preadipocytes. Consistent with previous reports ${ }^{22,23}$, ectopic expression of H3.3K36M selectively depleted global H3K36me2, mildly decreased H3K36me3 levels, and moderately increased H3K27me3 levels (Fig. 1a). Although the expression level of $\mathrm{H} 3.3 \mathrm{~K} 36 \mathrm{M}$ was much lower than that of endogenous H3 (Fig. 1a), it strongly inhibited adipogenesis and associated expression of adipogenesis markers Pparg, Cebpa, and Fabp4 (Fig. 1b, c). Ectopic expression of K36M of either histone H3.1 or H3.3 also strongly inhibited adipogenesis of 3T3-L1 white preadipocytes (Supplementary Fig. 1a-c), indicating that the K36M mutant of histone $\mathrm{H} 3$ inhibits both white and brown adipogenesis in culture. Retroviral vector-mediated expression of $\mathrm{H} 3.3 \mathrm{~K} 36 \mathrm{M}$ in C2C12 myoblasts also markedly inhibited myogenesis and the associated expression of myogenesis markers, such as Myog, Mck, and Myh (Supplementary Fig. 1d-f).

To understand how H3.3K $36 \mathrm{M}$ inhibits adipogenesis, cells were collected before (day 0, D0), during (day 2, D2), and after (day 7, D7) adipogenesis for RNA-sequencing (RNA-Seq) analysis. In cells expressing WT histone H3.3, 1610 (9.2\%) and $3348(19.1 \%)$ genes showed over twofold up-regulation and down-regulation, respectively, from D0 to D2. Among the 1610 up-regulated genes, 380 failed to be induced at D2 in K36Mexpressing cells, and therefore they are K36M-sensitive upregulated genes (Fig. 1d). Gene ontology (GO) analysis showed that only K36M-sensitive up-regulated genes were associated with fat cell differentiation (Fig. 1e). Consistent with the GO analysis results, K36M inhibits the induction of adipocyte genes $S c d 1$, Irs2, $L p l$, and Pgcla in addition to Cebpa (Fig. 1f).

Next, we performed chromatin immunoprecipitation followed by DNA sequencing (ChIP-Seq) to profile the chromatin landscape of $\mathrm{H} 3 \mathrm{~K} 36 \mathrm{me} 2$ and H3K27me3 in WT or K36M mutant of H3.3-expressing cells before (D0) and during (D2) adipogenesis. Because traditional ChIP-Seq analysis methods did not consider the global differences between samples, we further used quantification data from Western blot (Supplementary Fig. 2a, b) as a normalization Ctrl to achieve quantitative analysis of H3K27me3 and H3K36me2. Consistent with the Western blot results in Fig. 1a and Supplementary Fig. 2a, b, ChIP-Seq data showed that $\mathrm{H} 3.3 \mathrm{~K} 36 \mathrm{M}$ decreased $\mathrm{H} 3 \mathrm{~K} 36 \mathrm{me} 2$ but increased H3K27me3 on gene bodies (Supplementary Fig. 2c, d). Further analysis of H3K36me2 and H3K27me3 levels on K36M-sensitive or K36M-resistant genes during adipogenesis revealed that $\mathrm{H} 3.3 \mathrm{~K} 36 \mathrm{M}$ decreased the ratio of $\mathrm{H} 3 \mathrm{~K} 36 \mathrm{me} / \mathrm{H} 3 \mathrm{~K} 27 \mathrm{me} 3$ around the transcription start site of $\mathrm{K} 36 \mathrm{M}$-sensitive genes compared with H3.3WT (Supplementary Fig. 3). H3.3K36M only had mild effects on H3K36me2 and H3K27me3 levels on the Pparg gene locus by D2, which is consistent with the mild decrease of Pparg expression in $\mathrm{K} 36 \mathrm{M}$-expressing cells (Fig. 1g). In contrast, H3.3K36M notably decreased H3K36me2 but increased H3K27me3 levels on the gene locus encoding C/EBPa, another major regulator of adipogenesis and a direct target of PPAR $\gamma$, which correlates with the impaired Cebpa induction in H3.3K36M-expressing cells (Fig. 1g). Similar results were observed on gene loci encoding other adipogenesis markers and PPAR $\gamma$ targets such as Scd1, Lpl, and Pgcla (Supplementary Fig. 2e). Together, these results suggest that H3.3K36M inhibits 
adipogenesis by depleting $\mathrm{H} 3 \mathrm{~K} 36 \mathrm{me} 2$ and increasing $\mathrm{H} 3 \mathrm{~K} 27 \mathrm{me} 3$ to prevent the induction of $\mathrm{C} / \mathrm{EBP} a$ and other adipogenic genes.

H3.3K36M inhibits PPAR $\gamma$ target gene expression. Next, we investigated whether ectopic expression of adipogenic transcription factors $\mathrm{C} / \mathrm{EBPa}$ or PPAR $\gamma$ can rescue the adipogenesis defects in $\mathrm{H} 3.3 \mathrm{~K} 36 \mathrm{M}$-expressing preadipocytes (Supplementary
Fig. 4a and Fig. 2a). Ectopic expression of either C/EBPa or PPAR $\gamma$ failed to fully rescue the adipogenesis defect in H3.3K36M-expressing preadipocytes (Supplementary Fig. 4b, c and Fig. 2b, c). Since H3.3K36M impaired the induction of Cebpa and other PPAR $\gamma$ target genes during adipogenesis (Fig. 2c), we speculated that $\mathrm{H} 3.3 \mathrm{~K} 36 \mathrm{M}$ might inhibit PPAR $\gamma$ target gene activation. To test this possibility, we treated sub-confluent preadipocytes expressing ectopic PPAR $\gamma$ with $0.5 \mu \mathrm{M}$ PPAR $\gamma$ ligand

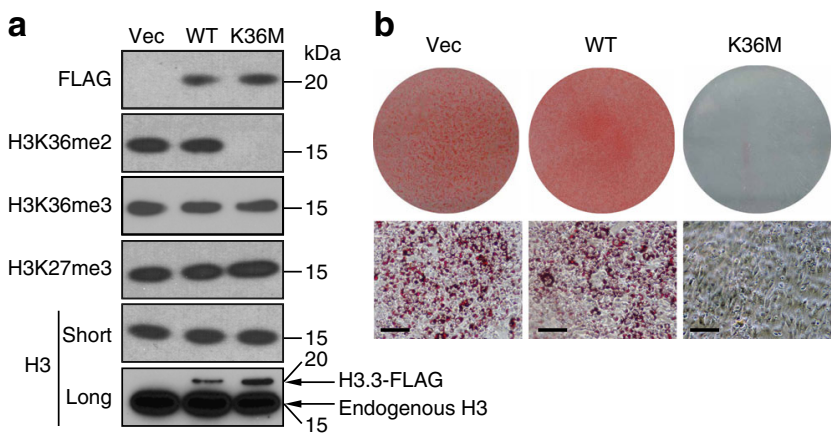

C
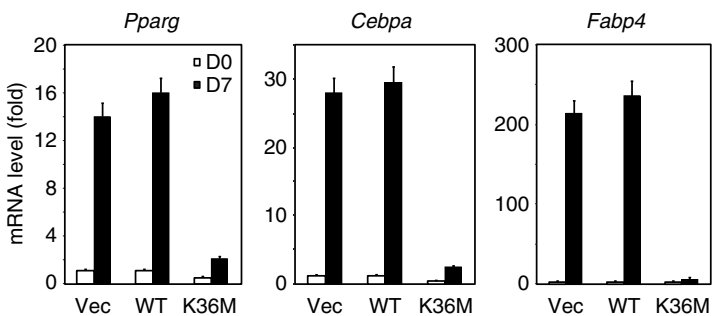

d RNA-Seq

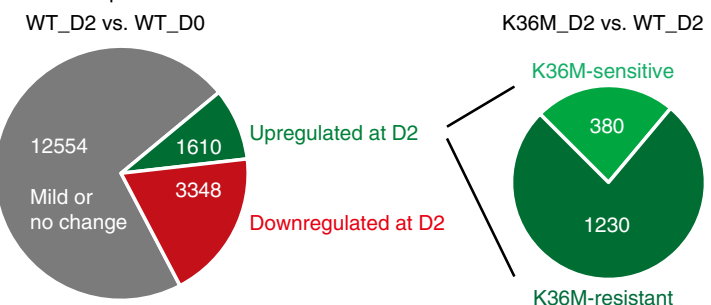

f
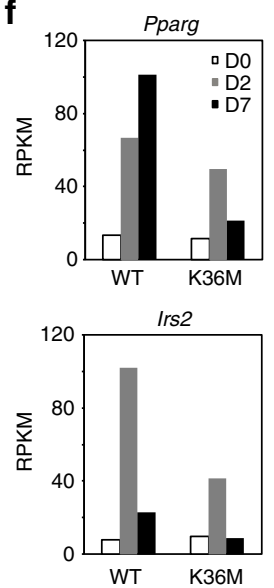

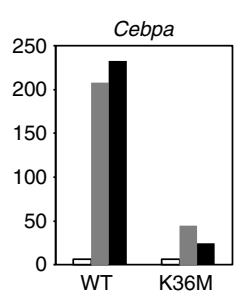

Lpl

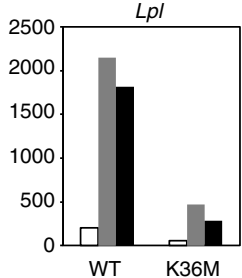

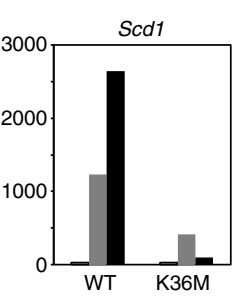

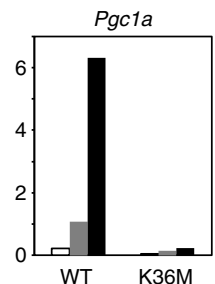

e

\begin{tabular}{lll}
\hline D2 & & \\
\hline Gene group & GO term & $P$ value \\
\hline & Brown fat cell differentiation & $6.0 \mathrm{E}-11$ \\
& Fat cell differentiation & $2.7 \mathrm{E}-10$ \\
Upregulated at D2 & Triglyceride metabolic process & $1.4 \mathrm{E}-08$ \\
(K36M-sensitive) & Acylglycerol metabolic process & $6.1 \mathrm{E}-08$ \\
& Neutral lipid metabolic process & $8.9 \mathrm{E}-08$ \\
& Glycerol ether metabolic process & $8.9 \mathrm{E}-08$ \\
\hline & Oxidation reduction & $2.6 \mathrm{E}-27$ \\
& Generation of precursor metabolites and energy & $3.0 \mathrm{E}-25$ \\
Upregulated at D2 & Electron transport chain & $8.0 \mathrm{E}-20$ \\
(K36M-resistant) & Coenzyme metabolic process & $2.6 \mathrm{E}-15$ \\
& Cofactor metabolic process & $1.3 \mathrm{E}-13$ \\
& Cellular respiration & $3.8 \mathrm{E}-12$ \\
\hline & Positive regulation of angiogenesis & $1.1 \mathrm{E}-19$ \\
& Cell adhesion & $4.9 \mathrm{E}-19$ \\
& Immune system process & $1.2 \mathrm{E}-17$ \\
& Angiogenesis & $8.3 \mathrm{E}-15$ \\
& Inflammatory response & $1.2 \mathrm{E}-14$ \\
& Response to virus & $3.3 \mathrm{E}-14$ \\
\hline
\end{tabular}

g

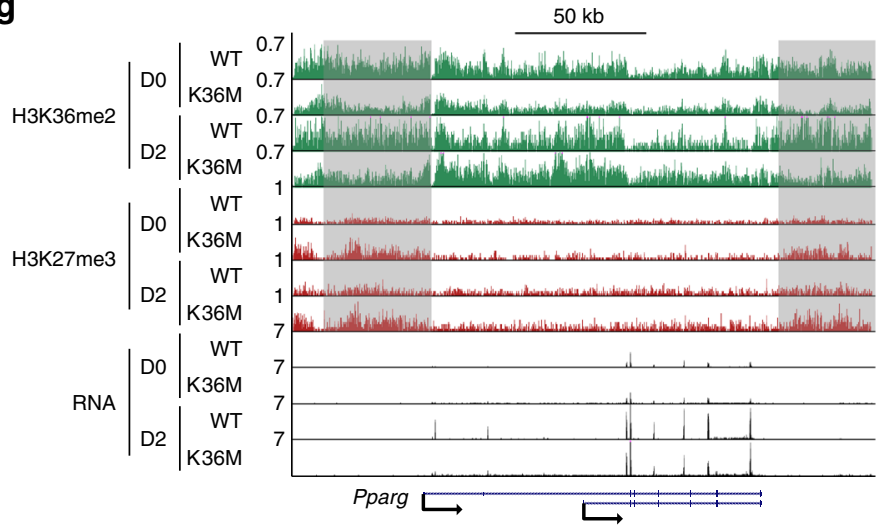

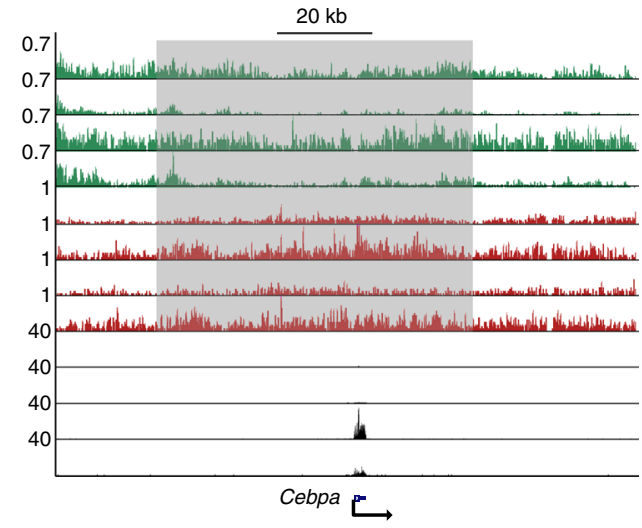


Rosiglitazone (Rosi) for $24 \mathrm{~h}$, followed by RNA-Seq analysis. After $24 \mathrm{~h}$ Rosi treatment, 1710 (10.3\%) and 925 (5.6\%) genes showed over twofold up-regulation and down-regulation, respectively. Among the 1710 up-regulated genes, 708 were induced in an H3.3K36M-sensitive manner (Fig. 2d). GO analysis showed that only H3.3K36M-sensitive genes were associated with fat cell differentiation (Fig. 2e). Consistent with the GO analysis results, K36M inhibited the ligand-induced expression of PPAR $\gamma$ target genes Cebpa, Scd1, Glut4, Irs2, Lpl, Adrb3, and Pgcla (Fig. 2f). These results indicate that H3.3K36M inhibits ligandinduced expression of PPAR $\gamma$ target genes critical for adipogenesis and adipocyte functions.

H3.3K36M targets Nsd2 to inhibit adipogenesis and PPAR $\gamma$. To identify the methyltransferases important for adipogenesis that are targeted by $\mathrm{H} 3.3 \mathrm{~K} 36 \mathrm{M}$, we individually knocked down (KD) the three major H3K36 methyltransferases Nsd1, Nsd2, and Setd2 in immortalized brown preadipocytes. Depletion of Nsd1 decreased H3K36me2 but increased H3K27me3 levels. Nsd2depleted preadipocytes showed more significant decrease of $\mathrm{H} 3 \mathrm{~K} 36 \mathrm{me} 2$ and increase of $\mathrm{H} 3 \mathrm{~K} 27 \mathrm{me} 3$ compared to depletion of Nsd1. Depletion of neither Nsd1 nor Nsd2 changed H3K36me3 levels (Supplementary Fig. 5a, d and Fig. 3a). In contrast, depletion of Setd 2 decreased H3K36me3 but had little effect on H3K36me2 and H3K27me3 levels (Supplementary Fig. 5g). Nsd1 or Setd $2 \mathrm{KD}$ did not affect cell growth rates. Although Nsd2 KD slightly decreased the growth rate of immortalized brown preadipocytes, these cells could grow to be over-confluent (Supplementary Fig. 6a). In adipogenesis assays, depletion of Nsd2 but not Nsd1 or Setd2 resulted in severe differentiation defects (Supplementary Fig. 5 and Fig. 3b).

By RNA-Seq analysis, we found that from D0 to D2 during adipogenesis, 1935 (11.4\%) and 2980 (17.5\%) genes showed over twofold up-regulation and down-regulation, respectively. Among the 1935 up-regulated genes, 507 were induced in an Nsd2dependent manner (Fig. 3c). GO analysis showed that only the Nsd2-dependent up-regulated gene group was highly associated with fat cell differentiation (Fig. 3d). By comparing the 507 Nsd2dependent and the $380 \mathrm{~K} 36 \mathrm{M}$-sensitive up-regulated genes (Fig. 1d) at D2 of adipogenesis, we found 150 genes shared by these two groups. Interestingly, Cebpa but not Pparg was among these 150 genes (Fig. 3e). Gene set enrichment analysis ${ }^{24}$ revealed that genes down-regulated by $N s d 2 \mathrm{KD}$ were significantly enriched among genes down-regulated by $\mathrm{H} 3.3 \mathrm{~K} 36 \mathrm{M}$ at D2 of adipogenesis. The GO analysis of core enrichment genes revealed fat cell differentiation as the top term (Supplementary Fig. 7). These data indicate that Nsd2 depletion mimics the effect of ectopic $\mathrm{H} 3.3 \mathrm{~K} 36 \mathrm{M}$ on repression of adipogenesis.

To determine whether the enzymatic activity of Nsd2 was required for adipogenesis, we used Clustered regularly interspaced short palindromic repeats (CRISPR) technology to generate $N s d 2$ knockout (KO) preadipocytes (Fig. 3f). Then, we generated two mutant forms of human NSD2, Y1092A/Y1179A (double mutant 1, DM1) and H1142G/Y1179A (DM2). Y1092A, H1142G, and Y1179A mutations have been shown to eliminate the H3K36 methyltransferase activity of NSD2 separately ${ }^{17,25}$. The Nsd2 KO preadipocytes were infected with retroviruses expressing either WT NSD2, DM1 or DM2. Western blot using an antibody that can detect both human and mouse Nsd 2 showed that expression level of ectopic NSD2 was similar to that of endogenous Nsd2 (Fig. 3f). Deletion of endogenous $N s d 2$ led to decreased H3K36me2 levels, which could be restored by expression of the WT but not the catalytic mutant forms of Nsd2 (Fig. 3f). Ectopic expression of WT NSD2, but not mutants, rescued the adipogenesis defects in $\mathrm{Nsd} 2 \mathrm{KO}$ preadipocytes (Fig. 3g, h), indicating that Nsd2 enzymatic activity is required for adipogenesis.

Consistent with the ChIP-Seq data from H3.3K36M-expressing cells (Fig. 1g and Supplementary Fig. 2e), ChIP-quantitative PCR (ChIP-qPCR) revealed that $\mathrm{H} 3 \mathrm{~K} 36 \mathrm{me} 2$ levels decreased and H3K27me3 levels increased on Cebpa, $L p l$, and Cd36, but not Pparg, gene loci in Nsd2-depleted preadipocytes (Supplementary Fig. 8). Furthermore, ectopic expression of either $\mathrm{C} / \mathrm{EBPa}$ or PPAR $\gamma$ failed to rescue adipogenesis defects in Nsd2-depleted preadipocytes (Supplementary Fig. 9). In addition, Nsd2-depleted preadipocytes showed severe defects in ligand-induced expression of PPAR $\gamma$ target genes Cebpa, Cd36, and $\mathrm{Lpl}$ (Fig. 3i). The results from Nsd2-depleted preadipocytes phenocopy those from H3.3K36M-expressing cells. Together, our data indicate that H3.3K36M targets Nsd2 to inhibit adipogenesis and PPAR $\gamma$ target gene expression.

H3.3K36M impairs BAT and muscle development. To find out whether depletion of $\mathrm{H} 3 \mathrm{~K} 36$ methylation inhibits adipogenesis in vivo, we generated a conditional $\mathrm{H} 3.3 \mathrm{~K} 36 \mathrm{M}$ transgenic mouse strain, LSL-K36M. The expression of FLAG-tagged H3.3K36M driven by a CAG promoter was blocked by the insertion of four copies of SV40 stop signals (STOP) flanked by two loxP sites (Fig. 4a). We crossed LSL-K36M with Myf5-Cre mice to delete the STOP cassette and induce H3.3K36M expression in progenitor cells of BAT and muscle lineages ${ }^{8,26}$. The resulting LSL-K36M; Myf5-Cre E18.5 embryos showed a slightly abnormal hunched posture due to reduction of back muscles (Fig. 4b). Immunohistochemical analysis of cervical regions of E18.5 embryos revealed that expression of $\mathrm{H} 3.3 \mathrm{~K} 36 \mathrm{M}$ in progenitor cells leads to reduction of BAT and muscle mass (Fig. 4c, d). Together with observations in cell culture (Fig. 1 and Supplementary Fig. 1), these data indicate that $\mathrm{H} 3 \mathrm{~K} 36$ methylation is essential for BAT and muscle development.

To confirm that the requirement of $\mathrm{H} 3 \mathrm{~K} 36$ methylation for adipogenesis and myogenesis is cell autonomous, we crossed LSLK36M with Cre-ER mice to obtain primary LSL-K36M;Cre-ER brown preadipocytes. After immortalization, cells were treated

Fig. 1 Expression of H3.3K36M in preadipocytes increases H3K27me3 to inhibit adipogenesis and adipogenic gene induction. a-c Ectopic expression of H3.3K36M in preadipocytes inhibits adipogenesis. SV40T-immortalized brown preadipocytes were infected with retroviral vector (Vec) expressing FLAGtagged wild-type (WT) or K36M mutant histone H3.3, followed by adipogenesis assay. a Western blot analysis of histone modifications. Histone extracts of preadipocytes were subjected to Western blot analysis using antibodies indicated on the left. me2 and me 3 refer to di-methylation and tri-methylation, respectively. Long exposure of histone $\mathrm{H} 3$ Western blot reveals the relative levels of ectopic $\mathrm{H} 3.3$ and endogenous H3. b Seven days after induction of differentiation, cells were stained with Oil Red O. Upper panels, stained dishes; lower panels, representative fields under microscope. Scale bars $=30 \mu \mathrm{m}$. $\mathbf{c}$ qRT-PCR of Pparg, Cebpa, and Fabp4 expression at day O (DO) and day 7 (D7) of adipogenesis. qRT-PCR data are presented as means \pm SEM. Three technical replicates from a single experiment were used. d-f WT and K36M cells were collected at D0, D2, and D7 for RNA-Seq analysis. d Schematic of identification of K36M-sensitive and K36M-resistant up-regulated genes at D2 of adipogenesis. The threshold for up-regulation or down-regulation is twofold. e Gene ontology (GO) analysis of gene groups defined in d. f Expression levels of representative genes are shown in RPKM (reads per kilo base of transcript per million mapped reads) values. $\mathbf{g}$ Genome browser views of ChIP-Seq and RNA-Seq data on Pparg and Cebpa loci during adipogenesis 
a

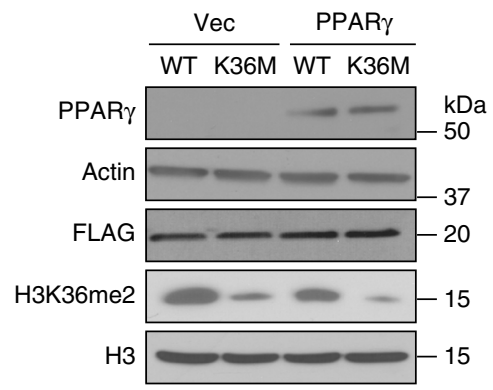

b

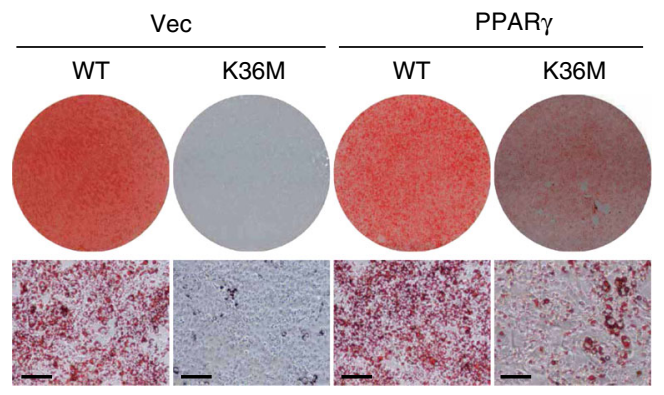

C
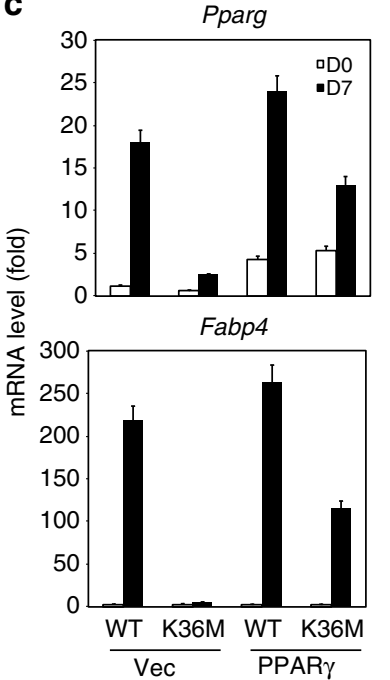

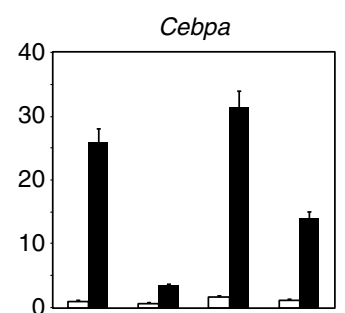

Ucp1

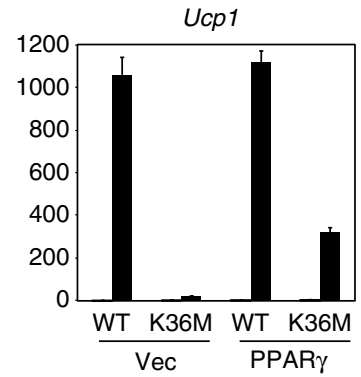

Sub-confluent preadipocytes expressing ectopic PPAR $\gamma \stackrel{\text { Rosi } 24 \mathrm{~h}}{\longrightarrow}$ RNA-Seq

d WT_Rosi vs. WT_DMSO

K36M_Rosi vs. WT_Rosi
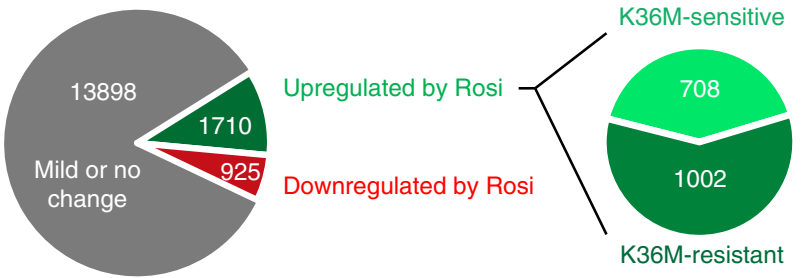

e

GO analysis

\begin{tabular}{clc}
\hline Gene group & GO term & p value \\
\hline & Brown fat cell differentiation & $3.5 \mathrm{E}-17$ \\
& Fat cell differentiation & $4.2 \mathrm{E}-15$ \\
Upregulated by Rosi & Response to hormone stimulus & $1.3 \mathrm{E}-10$ \\
(K36M-sensitive) & Response to endogenous stimulus & $1.1 \mathrm{E}-09$ \\
& Response to peptide hormone stimulus & $1.2 \mathrm{E}-08$ \\
& Response to insulin stimulus & $1.8 \mathrm{E}-08$ \\
\hline & Fatty acid metabolic process & $2.2 \mathrm{E}-07$ \\
Upregulated by Rosi & Oxidation reduction & $2.9 \mathrm{E}-06$ \\
(K36M-resistant) & Carboxylic acid transport & $5.0 \mathrm{E}-06$ \\
& Organic acid transport & $5.6 \mathrm{E}-06$ \\
& Response to virus & $7.5 \mathrm{E}-06$ \\
& Amino acid transport & $1.2 \mathrm{E}-04$ \\
\hline & Positive regulation of stress fiber assembly & $4.4 \mathrm{E}-08$ \\
& Cell migration & $5.7 \mathrm{E}-08$ \\
Downregulated by & Cell differentiation & $1.0 \mathrm{E}-07$ \\
Rosi & Cell adhesion & $1.6 \mathrm{E}-07$ \\
& Angiogenesis & $2.0 \mathrm{E}-07$ \\
& Positive regulation of cell migration & $7.0 \mathrm{E}-07$ \\
\hline
\end{tabular}

f
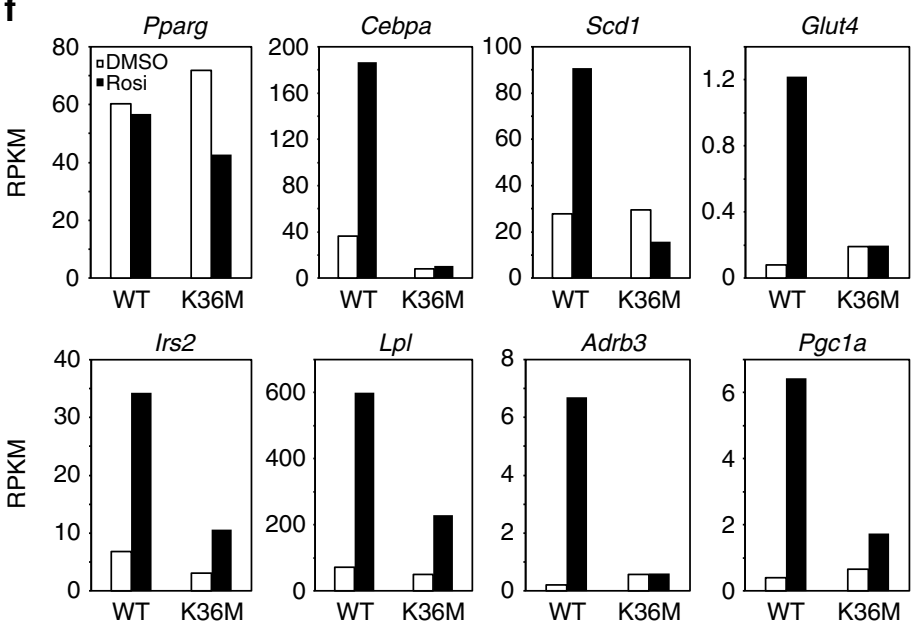

Fig. 2 H3.3K36M inhibits ligand-induced PPAR $y$ target gene expression. Immortalized brown preadipocytes were infected with retroviral vector expressing FLAG-tagged WT or K36M mutant histone H3.3. After puromycin selection, cells were infected with retroviral vector expressing PPAR $\gamma$ or empty vector, followed by hygromycin selection. a Western blot analysis in preadipocytes using antibodies indicated on the left. b Oil Red O staining at D7 of adipogenesis. Scale bars $=30 \mu \mathrm{m}$. c qRT-PCR of Pparg, Cebpa, Fabp4, and Ucp1 expression at D0 and D7 of adipogenesis. qRT-PCR data are presented as means \pm SEM. Three technical replicates from a single experiment were used. d-f Sub-confluent preadipocytes expressing ectopic PPAR $\gamma$ were treated with DMSO or $0.5 \mu \mathrm{M}$ PPAR ligand Rosiglitazone (Rosi) for $24 \mathrm{~h}$, followed by RNA-Seq analysis. d Schematic of identification of K36M-sensitive and K36Mresistant genes up-regulated by Rosi treatment. The threshold for up-regulation or down-regulation is twofold. e GO analysis of gene groups defined in d. $\mathbf{f}$ RPKM values of Pparg and representative PPAR $\gamma$ target genes from RNA-Seq analysis

with 4-hydroxytamoxifen (4OHT) to delete the STOP cassette and induce $\mathrm{H} 3.3 \mathrm{~K} 36 \mathrm{M}$ expression (Fig. 4e), followed by adipogenesis assay. Consistent with the data from LSL-K36M; Myf5-Cre mice, expression of H3.3K36M inhibited adipogenesis and the induction of adipocyte marker genes such as Pparg, Cebpa, and Fabp4 (Fig. 4f, g). For myogenesis, ectopic MyoD was expressed in the immortalized LSL-K36M;Cre-ER preadipocytes. 4OHT-induced H3.3K36M expression (Fig. 4h) inhibited MyoD- 
a

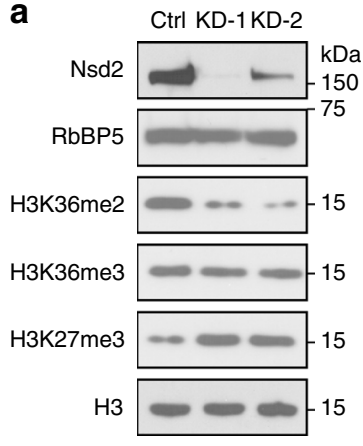

C RNA-Seq

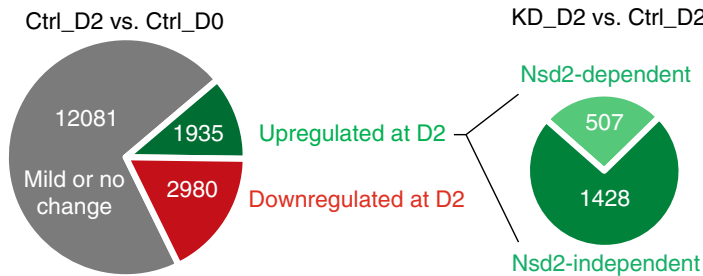

d GO analysis

\begin{tabular}{lll}
\hline Gene group & Go term & p value \\
\hline & Brown fat cell differentiation & $8.7 \mathrm{E}-14$ \\
& Fat cell differentiation & $7.7 \mathrm{E}-12$ \\
Upregulated at D2 & Response to hormone stimulus & $3.3 \mathrm{E}-09$ \\
(Nsd2-dependent) & Response to endogenous stimulus & $1.9 \mathrm{E}-08$ \\
& Response to peptide hormone stimulus & $2.2 \mathrm{E}-06$ \\
& Cation homeostasis & $3.0 \mathrm{E}-06$ \\
\hline & tRNA metabolic process & $3.6 \mathrm{E}-09$ \\
& ncRNA metabolic process & $1.0 \mathrm{E}-08$ \\
Upregulated at D2 & tRNA aminoacylation for protein translation & $1.3 \mathrm{E}-06$ \\
(Nsd2-independent) & tRNA aminoacylation & $1.3 \mathrm{E}-06$ \\
& Amino acid activation & $1.3 \mathrm{E}-06$ \\
& L-serine metabolic process & $5.0 \mathrm{E}-06$ \\
\hline & Actin filament-based process & $5.9 \mathrm{E}-14$ \\
& Cytoskeleton organization & $1.9 \mathrm{E}-13$ \\
Downregulated at D2 & Actin cytoskeleton organization & $2.1 \mathrm{E}-13$ \\
& Intracellular signaling cascade & $6.4 \mathrm{E}-11$ \\
& Blood vessel morphogenesis & $1.2 \mathrm{E}-10$ \\
& Vasculature development & $2.4 \mathrm{E}-10$ \\
& &
\end{tabular}

e

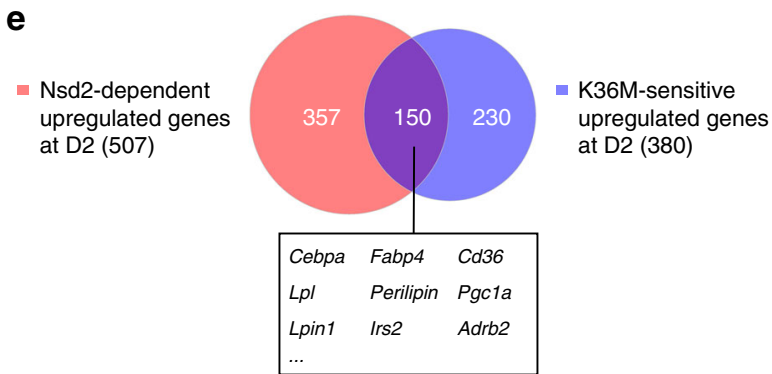

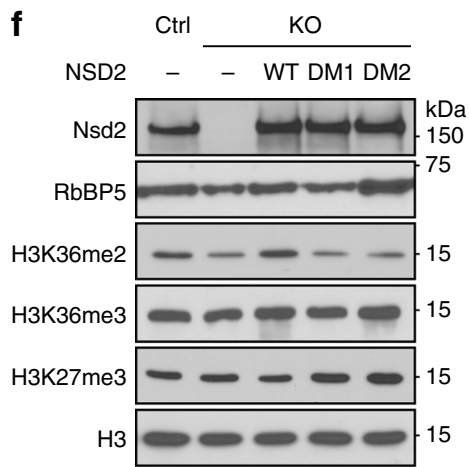

g

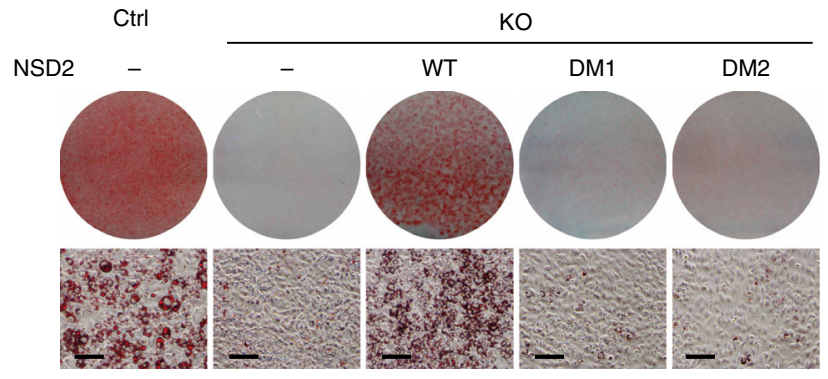

h
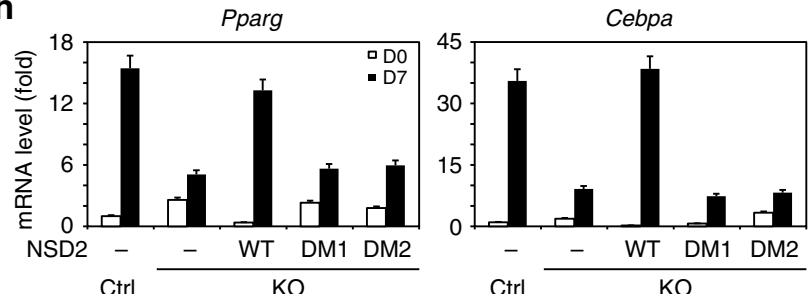

i

Sub-confluent preadipocytes expressing ectopic PPAR $\gamma \stackrel{\text { Rosi } 24 \mathrm{~h}}{\longrightarrow}$ qPCR

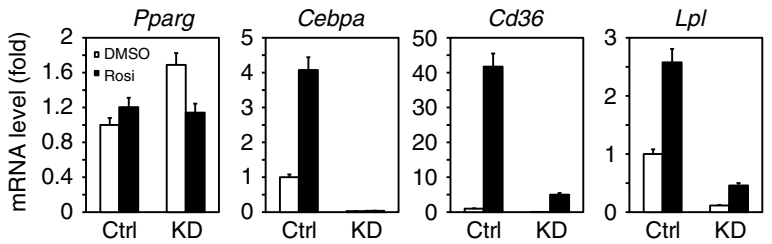

Fig. 3 H3.3K36M targets H3K36 methyltransferase Nsd2 to inhibit adipogenesis and PPAR $\gamma$ target gene expression. a-e Immortalized brown preadipocytes were infected with lentiviral vector expressing control (Ctrl) or Nsd2 knockdown (KD) shRNAs, followed by adipogenesis assay until D7. Cells were collected at D0 and D2 for RNA-Seq. a Western blot of Nsd2 and histone methylations in preadipocytes. RbBP5 and histone H3 were used as loading controls. b Oil Red O staining at D7 of adipogenesis. Scale bars $=30 \mu \mathrm{m}$. c Schematic identification of Nsd2-dependent and Nsd2-independent upregulated genes at D2 of adipogenesis. The threshold for up-regulation or down-regulation is twofold. $\mathbf{d} \mathrm{GO}$ analysis of gene groups defined in $\mathbf{c}$. e Venn diagram depicting Nsd2-dependent (507) and K36M-sensitive (380) up-regulated genes at D2. f-h Nsd2 methyltransferase activity is required for adipogenesis. Nsd2 knockout (KO) preadipocytes were generated using CRISPR. Control (Ctrl) and Nsd2 KO cells were infected with retroviral vector expressing either WT, Y1092A/Y1179A mutant (DM1), or H1042G/Y1179A mutant (DM2) human NSD2, followed by adipogenesis assay. $\mathbf{f}$ Western blot of Nsd2 and histone methylations in preadipocytes. $\mathbf{g}$ Cells were stained with Oil Red O at D7 of adipogenesis. Scale bars $=30 \mu \mathrm{m}$. $\mathbf{h}$ qRT-PCR of Pparg and Cebpa expression at D0 and D7 of adipogenesis. i Nsd2 is required for ligand-induced PPAR $y$ target gene expression. Ctrl or Nsd2 KD preadipocytes were infected with retroviral vector expressing PPAR $\gamma$. Sub-confluent cells were treated with DMSO or $0.5 \mu$ M Rosi for $24 \mathrm{~h}$, followed by qRT-PCR of Pparg and its target genes Cebpa, Cd36, and Lpl. All qRT-PCR data are presented as means \pm SEM. Three technical replicates from a single experiment were used 
a

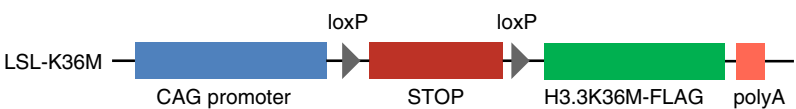

b E18.5 embryos

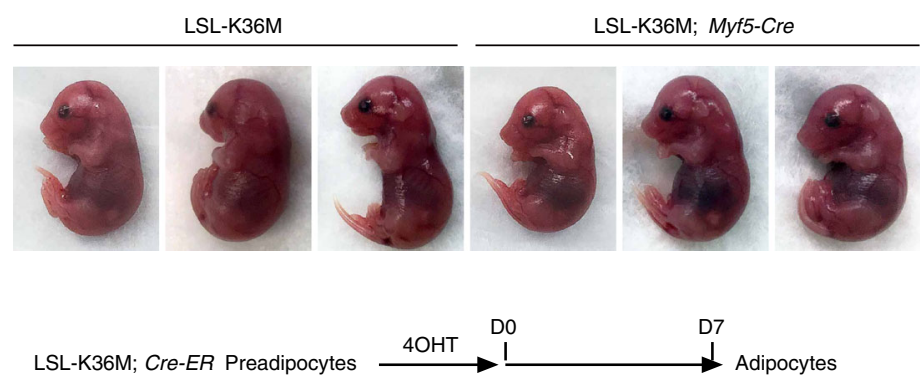

C $_{\text {H\&E }}$

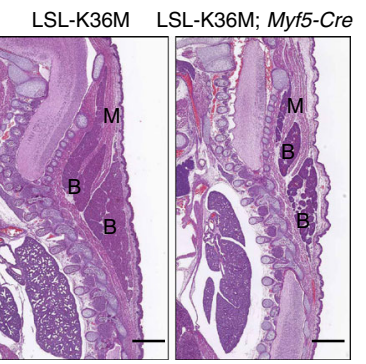

d $_{\text {IHC }}$

LSL-K36M LSL-K36M; Myf5-Cre

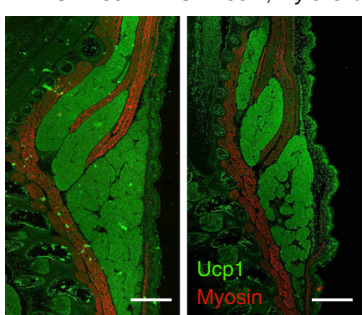

e

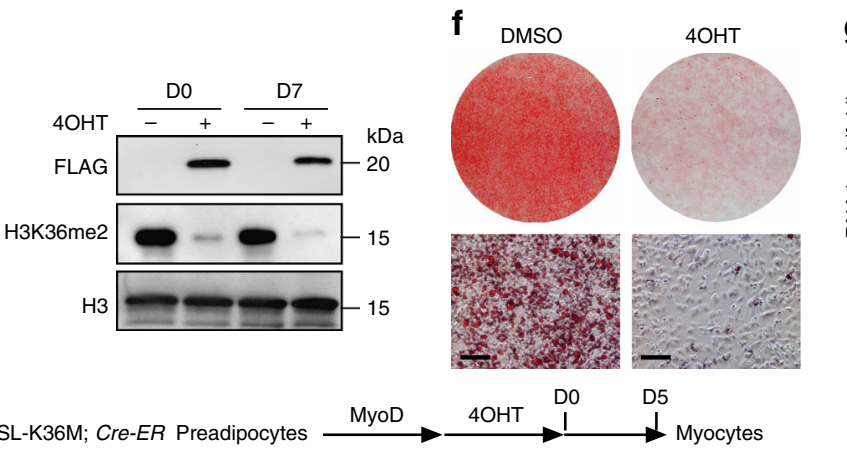

h

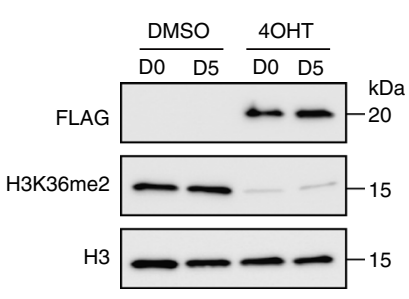

i

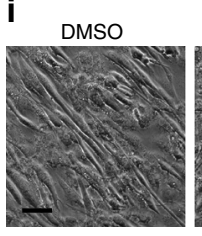

4OHT

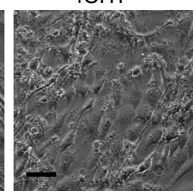

j

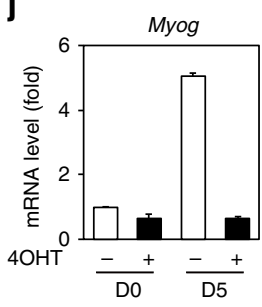

g
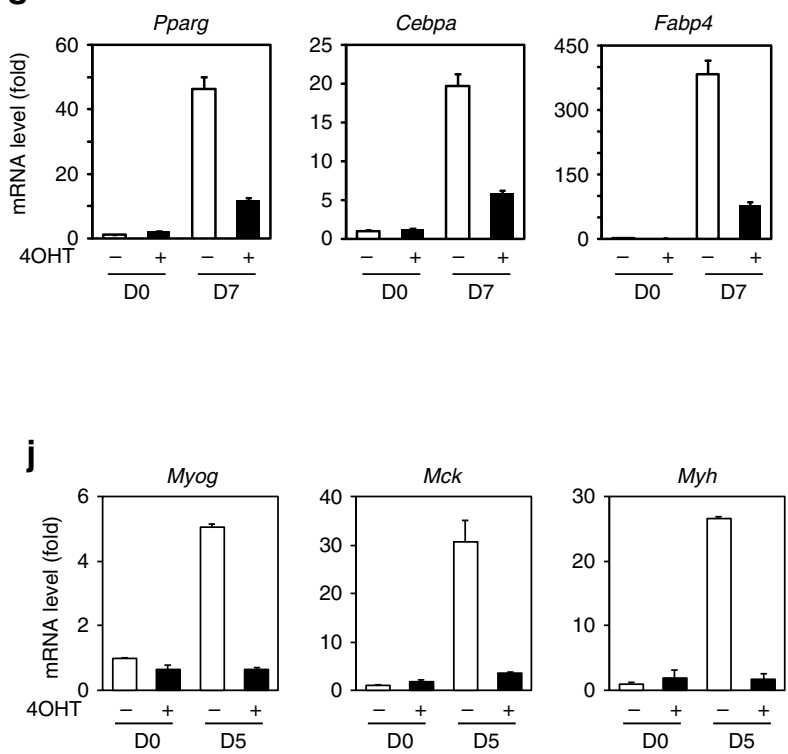

Fig. 4 Expression of H3.3K36M in $\mathrm{Myf5}^{+}$progenitor cells impairs brown adipose tissue and muscle development. a Schematic of the LSL-K36M transgenic construct. The LSL-K36M transgene consists of the following elements from 5' to 3': CAG promoter, four copies of SV40 stop signals (STOP) flanked by two loxP sites, H3.3K36M with FLAG tag, and polyA. b-d LSL-K36M were crossed with Myf5-Cre to generate LSL-K36M;Myf5-Cre mice expressing H3.3K36M in progenitor cells of brown adipose tissue (BAT) and muscle. b Representative morphology of E18.5 embryos. c, d Histological analysis of E18.5 embryos. Sagittal sections of cervical/thoracic area were stained with H\&E (c), or with antibodies against the BAT (B) marker Ucp1 (green) and the muscle (M) marker Myosin (red) (d). Scale bar $=300 \mu \mathrm{m}$. e-g LSL-K36M were crossed with Cre-ER to generate LSL-K36M;Cre-ER mice. Primary brown preadipocytes were isolated from newborn pups. After SV4OT immortalization, cells were treated with 4-hydroxytamoxifen (4OHT) to induce H3.3K36M expression, followed by adipogenesis assay. e Western blot in LSL-K36M;Cre-ER preadipocytes (DO) and adipocytes (D7). f Oil Red O staining at D7 of adipogenesis. Scale bars $=30 \mu \mathrm{m}$. g qRT-PCR of Pparg, Cebpa, and Fabp4 expression at DO and D7 of adipogenesis. h-j Immortalized LSL-K36M;Cre-ER preadipocytes were infected with retroviral vector expressing MyoD. After puromycin selection, cells were treated with $4 \mathrm{OHT}$ to induce $\mathrm{H3} .3 \mathrm{~K} 36 \mathrm{M}$ expression, followed by myogenesis assay. $\mathbf{h}$ Western blot in LSL-K36M;Cre-ER preadipocytes (day 0, D0) and myocytes (day 5, D5). i Cell morphologies were observed under a microscope at D5 of myogenesis. Scale bars $=20 \mu \mathrm{m}$. $\mathbf{g}$ qRT-PCR analysis of myogenic gene expression at D0 and D5 of myogenesis. All qRT-PCR data are presented as means \pm SEM. Three technical replicates from a single experiment were used

driven myogenesis and the induction of myogenic genes such as Myog, Mck, and Myh (Fig. 4i, j).

Adipose-selective expression of $\mathrm{H} 3.3 \mathrm{~K} 36 \mathrm{M}$ reprograms BAT. Next, we investigated the role of H3K36 methylation in adipose tissue functions in mice. For this purpose, we generated another transgenic mouse strain, A-K36M, in which the expression of FLAG-tagged H3.3K36M was driven by the $7.9 \mathrm{~kb}$ adiposeselective Fabp4 (aP2) promoter described previously ${ }^{27}$ (Fig. 5a). Different from LSL-K36M;Myf5-Cre mice, newborn A-K36M pups did not show significant defects in BAT development
(Supplementary Fig. 10a). While H3.3K36M was undetectable in primary A-K36M brown preadipocytes, its level increased dramatically, which caused depletion of H3K36me2 after 7 days of adipogenesis (Supplementary Fig. 10b). Consistent with the observation from newborn pups, H3.3K36M expression only mildly reduced lipid accumulation and the induction of adipocyte marker genes Pparg and Cebpa after adipogenesis (Supplementary Fig. 10c, d).

In adult $\mathrm{A}-\mathrm{K} 36 \mathrm{M}$ mice, $\mathrm{H} 3.3 \mathrm{~K} 36 \mathrm{M}$ was detected by Western blot in interscapular BAT, inguinal WAT (ing-WAT) and epididymal WAT (epi-WAT) but not in non-adipose tissues examined (Fig. 5b). Fabp4 promoter-driven expression of 
$\mathrm{H} 3.3 \mathrm{~K} 36 \mathrm{M}$ depleted endogenous $\mathrm{H} 3 \mathrm{~K} 36 \mathrm{me} 2$ and $\mathrm{H} 3 \mathrm{~K} 36 \mathrm{me} 3$ and mildly increased $\mathrm{H} 3 \mathrm{~K} 27 \mathrm{me} 3$ in the BAT of A-K36M mice (Fig. 5c). Compared with WT Ctrl, A-K36M mice did not show significant changes in food intake, energy expenditure, activity, or $\mathrm{O}_{2}$ consumption, although the respiratory exchange ratio increased slightly (Supplementary Fig. 11a-e). A-K36M mice showed similar body weight and fat and lean mass compared to that of Ctrl mice at 8 weeks of age (Fig. 5d). The weight and size of the BAT, WATs, and other tissues were similar between A$\mathrm{K} 36 \mathrm{M}$ and Ctrl mice (Fig. 5e, f). These results indicate that Fabp4 promoter-driven $\mathrm{H} 3.3 \mathrm{~K} 36 \mathrm{M}$ expression has minimal effects on adipose tissue development. a

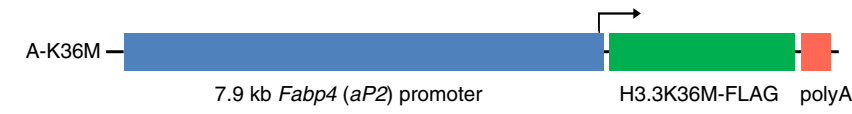

b

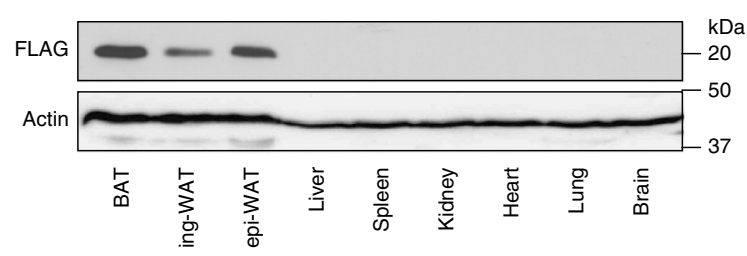

d
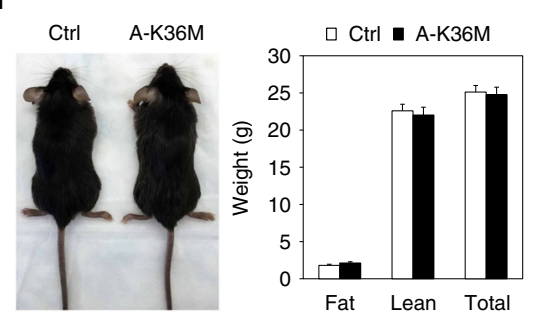

e

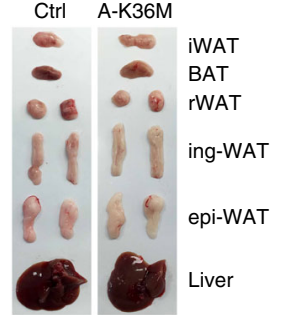

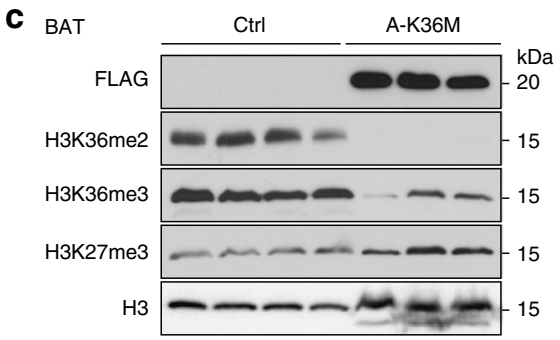

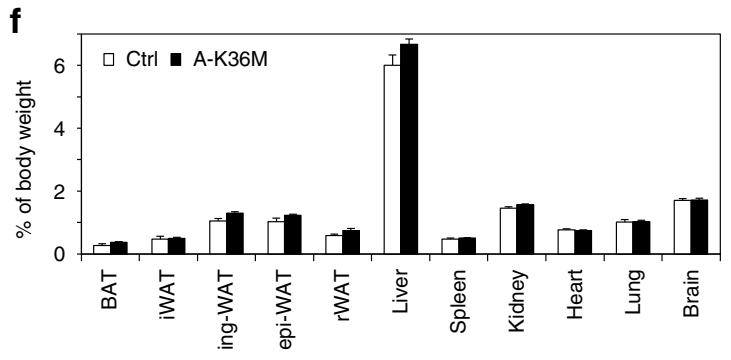

g BAT Ctrl

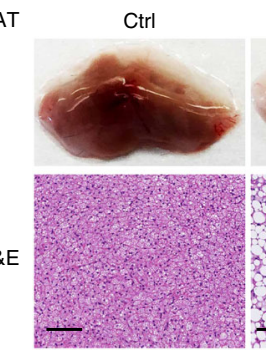

$\mathbf{j}_{\text {RNA-Seq }}$
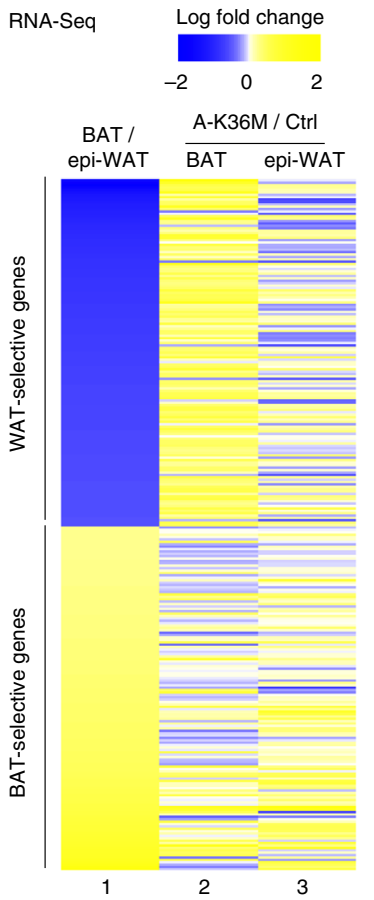

A-K36M

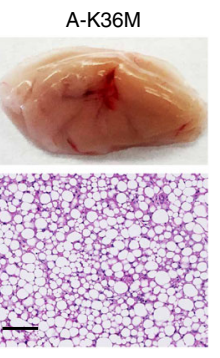

h

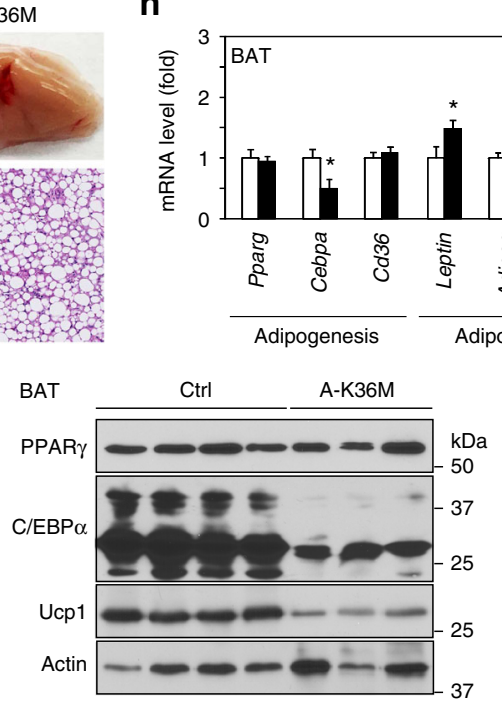

K WAT-selective genes
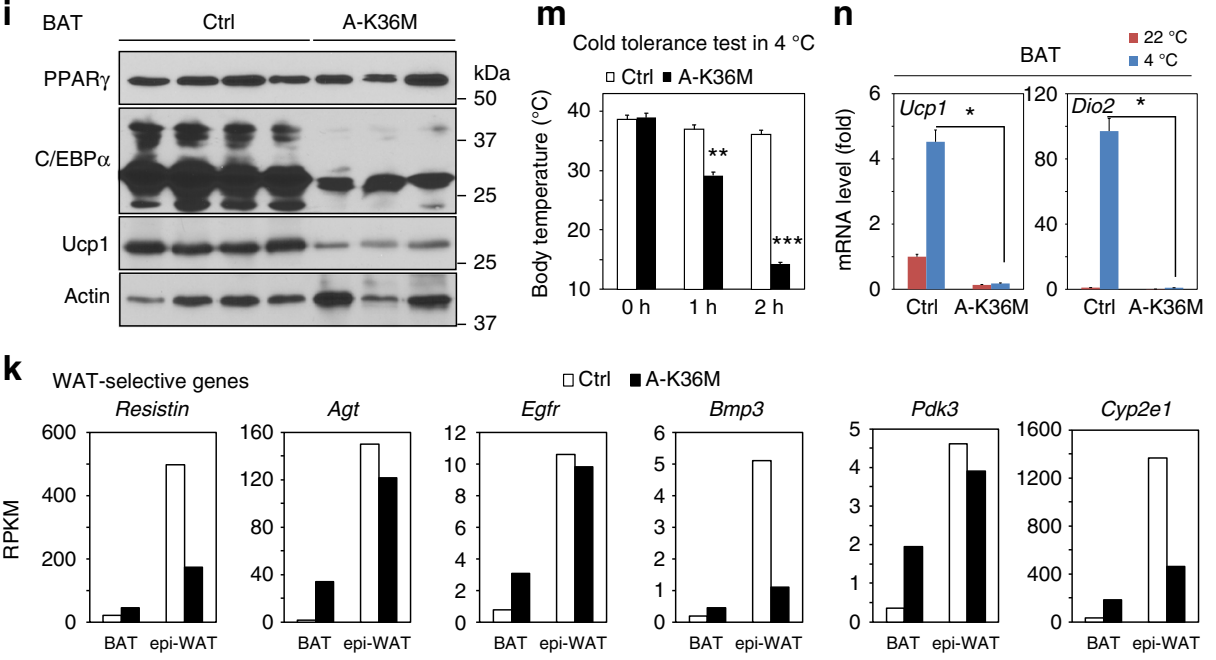

$\square$ Ctrl $\square$ A-K36M

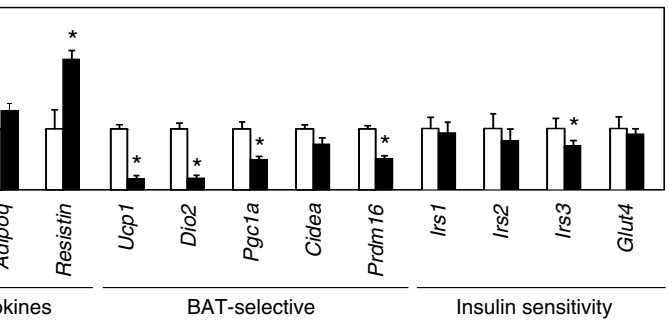

m
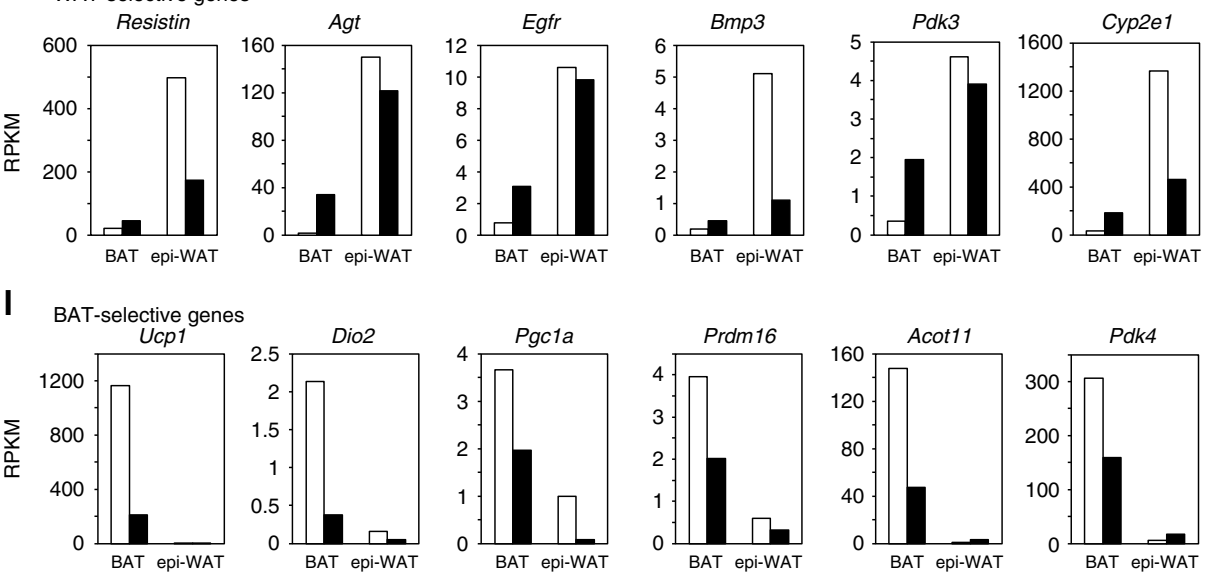
Interestingly, the BAT of A-K36M mice showed whitening in color and increased lipid accumulation (Fig. 5g). Expression levels of Cebpa and BAT-selective genes Ucp1, Dio2, Pgc1a, and Prdm16 decreased in the BAT of A-K36M mice, while Pparg levels remained similar (Fig. 5h). Decreased expression of C/EBPa and Ucp1 but not PPAR $\gamma$ was confirmed by Western blot (Fig. 5i) and/or immunostaining (Supplementary Fig. 11f). In addition, expression of Leptin and Resistin, which are normally enriched in WAT, increased in the BAT of A-K36M mice (Fig. 5h). Consistently, H3.3K36M increased the expression of WATselective genes Resistin and Agt but reduced the expression of BAT-selective genes Ucp1 and Pgcla after adipogenesis of primary A-K36M brown preadipocytes (Supplementary Fig. 10d). $\mathrm{H} 3 \mathrm{~K} 36 \mathrm{me} 2$ levels decreased while H3K27me3 levels increased on Cebpa, Pgc1a, and Ucp1, but not Pparg gene loci in both brown A-K36M adipocytes differentiated in culture and BAT of AK36M mice (Supplementary Fig. 10e, f).

To further investigate the gene expression profile changes, BAT and epi-WAT were collected from A-K36M and Ctrl mice for RNA-Seq. We first determined the top 1000 WAT-selective and BAT-selective genes by comparing the transcriptomes of BAT and epi-WAT in Ctrl mice (Fig. 5j, column 1). The majority of WAT-selective genes (813) were up-regulated more than twofold in the BAT of A-K36M mice (Fig. 5j, column 2 and Fig. 5k), whereas BAT-selective genes showed reduced expression (Fig. 5l). These data suggest that depletion of $\mathrm{H} 3 \mathrm{~K} 36$ methylation by $\mathrm{H} 3.3 \mathrm{~K} 36 \mathrm{M}$ causes reprogramming of the BAT gene expression profile and whitening of BAT.

A-K36M mice maintained core body temperatures when housed at room temperature $\left(\sim 22^{\circ} \mathrm{C}\right)$. However, their core body temperatures dropped to $\sim 28^{\circ} \mathrm{C}$ after $1 \mathrm{~h}$ and to $\sim 15^{\circ} \mathrm{C}$ after $2 \mathrm{~h}$ exposure to an ambient temperature of $4{ }^{\circ} \mathrm{C}$ (Fig. $5 \mathrm{~m}$ ). Expression levels of thermogenesis genes Ucp1 and Dio2 decreased in both BAT (Fig. 5n) and ing-WAT (Supplementary Fig. 11g) of A$\mathrm{K} 36 \mathrm{M}$ mice at room temperature and failed to induce after $2 \mathrm{~h}$ cold exposure, indicating thermogenesis defects in both BAT and ing-WAT of A-K36M mice. Lipolysis is critical for thermogenesis in mice ${ }^{4}$. Activation of the $\beta 3$-adrenergic signaling pathway by CL316,243 (CL), a selective $\beta 3$-adrenergic receptor agonist, increases lipolysis and free fatty acid (FFA) release and induces energy expenditure to generate heat ${ }^{28}$. We found that the administration of CL increased total energy expenditure in Ctrl, but not in A-K36M mice (Supplementary Fig. 11h). A-K36M mice also showed defects in CL-stimulated lipolysis, indicated by reduced FFA release (Supplementary Fig. 11i). Together, data from A-K36M mice suggest that adipose-selective expression of $\mathrm{H} 3.3 \mathrm{~K} 36 \mathrm{M}$ depletes $\mathrm{H} 3 \mathrm{~K} 36$ methylation and reprograms BAT gene expression, which has minimal effects on adipose tissue development but leads to severe thermogenesis defects in BAT.
A-K36M mice show insulin resistance in WAT. Next, we analyzed WAT of A-K36M mice. Hematoxylin and eosin (H\&E) staining of ing-WAT and epi-WAT sections revealed similar sizes of adipocytes between A-K36M and Ctrl mice (Fig. 6a). Similar $\mathrm{H} \& \mathrm{E}$ staining results and triglyceride contents were observed in the liver of A-K36M and Ctrl mice (Fig. 6b). Levels of adiponectin, but not leptin, were decreased in the serum of A-K36M mice (Fig. 6c). FFA, triglyceride, and cholesterol levels in serum were similar between A-K36M and Ctrl mice (Fig. 6d). However, the expression levels of adipogenesis markers Pparg, Cebpa, and Cd36, lipolysis genes $L p l, H s l$, and $A d r b 3$, and adipokines Adiponectin (Adipoq) and Resistin were decreased in both ing-WAT and epi-WAT of A-K36M mice (Fig. 6e), suggesting that depletion of H3K36 methylation by $\mathrm{H} 3.3 \mathrm{~K} 36 \mathrm{M}$ impairs WAT gene expression.

In addition, insulin signaling pathway genes Irs 1 and Irs 2 were expressed at markedly lower levels in WATs (Fig. 6e), but not BAT (Fig. 5h), of A-K36M mice compared to Ctrl, suggesting impaired insulin sensitivity in A-K36M mice. Indeed, glucose tolerance test (GTT) (Fig. 6f) and insulin tolerance test (ITT) (Fig. 6g) showed that A-K36M mice were insulin resistant. Under randomly fed status or after $4 \mathrm{~h}$ fasting, the blood glucose levels were similar between A-K36M and Ctrl mice (Fig. 6h). However, the serum insulin levels in A-K36M mice were much higher (Fig. 6i), indicating that A-K36M mice need more insulin to maintain similar levels of blood glucose. Western blot of insulinstimulated phosphorylation of Akt confirmed impaired insulin signaling in ing-WAT and epi-WAT, but not BAT and liver, of AK36M mice (Fig. 6j). These data indicate that although adiposeselective expression of $\mathrm{H} 3.3 \mathrm{~K} 36 \mathrm{M}$ has minimal effects on WAT development, it inhibits insulin signaling pathway gene expression in WATs, which leads to insulin resistance in mice.

A-K36M mice are resistant to HFD-induced WAT expansion. After analyzing A-K36M mice under regular diet (RD), we examined them under high fat diet (HFD) for 10 to 11 weeks. AK36M mice showed significantly less body weight and fat mass, but not lean mass, than the Ctrl after HFD (Fig. 7a, b and Supplementary Fig. 12a). Ctrl and A-K36M mice had similar food intakes under $\mathrm{RD}$ or $\mathrm{HFD}$, but A-K36M mice had higher accumulative energy expenditure compared with Ctrl mice when they were fed with HFD (Supplementary Fig. 12b, c). The ing-WAT and epi-WAT were much smaller, while the liver was much larger in A-K36M mice (Fig. 7c). Adipocytes in ing-WAT and epi-WAT of A-K36M mice were smaller, but there was more lipid accumulation in the liver (Fig. 7d). These results indicate a failure in the expansion of adipose tissues and a fatty liver phenotype in the A-K36M mice after HFD. Consistent with the markedly reduced

Fig. 5 Adipose-selective expression of H3.3K36M depletes H3K36 methylation and reprograms BAT. a Schematic of transgenic (A-K36M) construct. Expression of FLAG-tagged H3.3K36M is under the control of the $7.9 \mathrm{~kb}$ adipose tissue-selective Fabp4 promoter. b Tissue distribution of FLAG-tagged H3.3K36M in A-K36M mice was determined by Western blot. All data in this figure were from 8-week-old to 10-week-old male mice fed with regular diet. c Western blot in BAT of control (Ctrl) and A-K36M mice. d Representative picture of Ctrl and A-K36M mice (left). Fat mass, lean mass, and total body weight of $\mathrm{Ctrl}$ and A-K36M mice ( $n=6$ per group) were measured by MRI (right). e Representative pictures of interscapular WAT (iWAT), BAT, retroperitoneal WAT (rWAT), inguinal WAT (ing-WAT), epididymal WAT (epi-WAT), and liver. f Average tissue weights in Ctrl and A-K36M mice ( $n=6$ per group) are presented as \% of body weight. $\mathbf{g}$ Enlarged images (upper panels) and H\&E staining (lower panels) of BAT isolated from Ctrl and A-K36M mice. Scale bar $=100 \mu \mathrm{m}$. $\mathbf{h}$ qRT-PCR analysis in BAT of Ctrl and A-K36M mice ( $n=6$ per group). i Western blot of PPAR $\gamma, \mathrm{C} / E B P \alpha$, and Ucp1 in BAT isolated from Ctrl and A-K36M mice. $\mathbf{j}-\mathbf{I}$ BAT and epi-WAT were collected from A-K36M and Ctrl mice for RNA-Seq. $\mathbf{j}$ Heatmaps of BAT-enriched or epiWAT-enriched genes. Column 1, log fold change between RPKM of BAT vs. epi-WAT in Ctrl mice. Top 1000 WAT-selective or top 1000 BAT-selective genes were analyzed. Columns 2-3, log fold change between RPKM of A-K36M vs. Ctrl mice (A-K36M/Ctrl) in BAT (column 2) or epi-WAT (column 3). k, I RPKM values of WAT-selective (k) or BAT-selective (I) genes. $\mathbf{m}, \mathbf{n}$ Cold tolerance test. Ctrl and A-K36M mice ( $n=6$ per group) were housed at room temperature $\left(22^{\circ} \mathrm{C}\right)$ or in cold $\left(4^{\circ} \mathrm{C}\right)$ for $2 \mathrm{~h}$. $\mathbf{m}$ Body temperatures. $\mathbf{n}$ qRT-PCR of Ucp1 and Dio2 in BAT. All values in $\mathbf{d}, \mathbf{f}, \mathbf{h}$ and $\mathbf{m}, \mathbf{n}$ are presented as mean \pm SEM. Statistical comparison between groups was performed using Student's $t$ test. ${ }^{\star} p<0.05,{ }^{\star \star} p<0.01$, and ${ }^{\star \star \star} p<0.005$ 


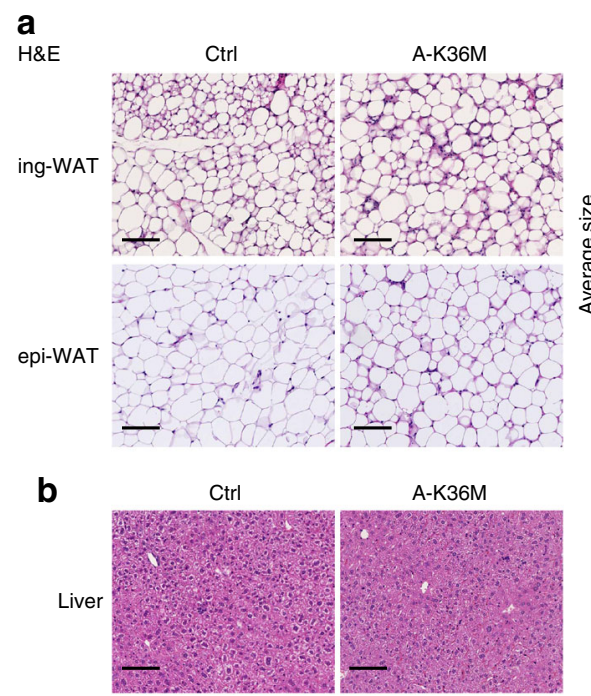

e
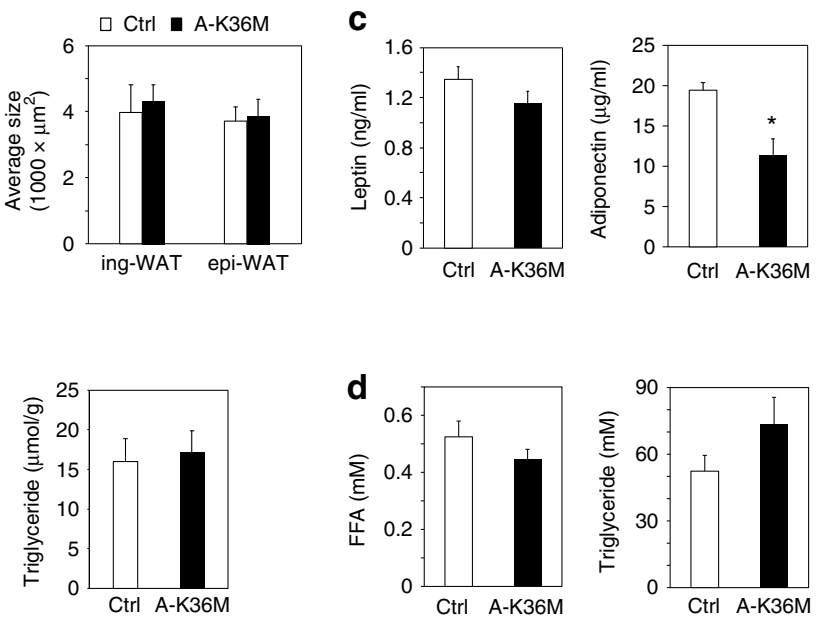

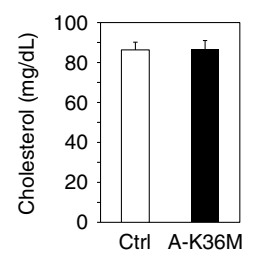

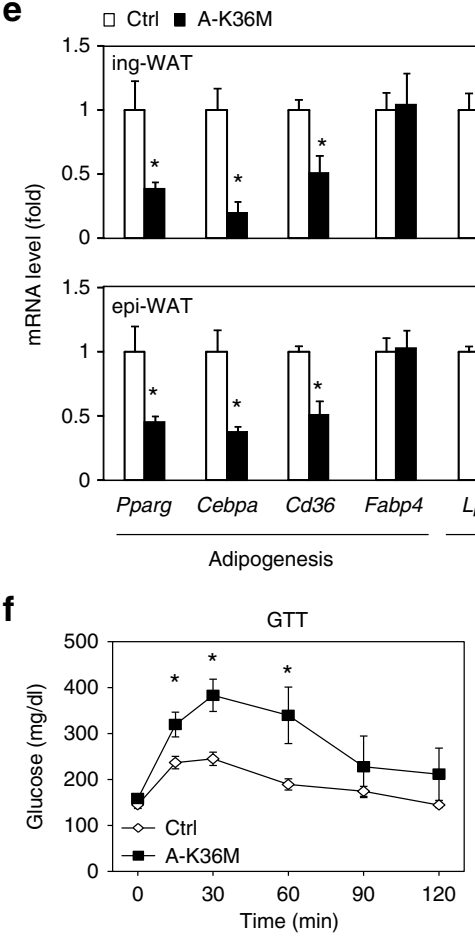

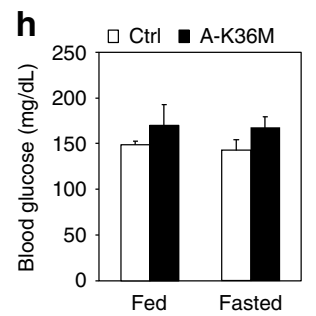

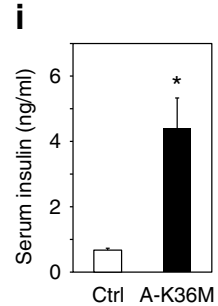

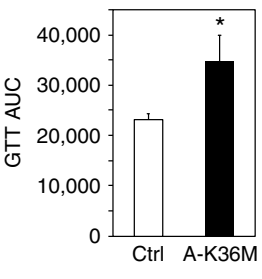

j

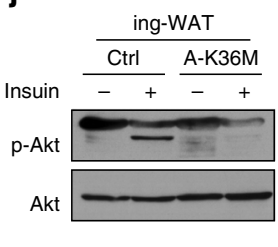

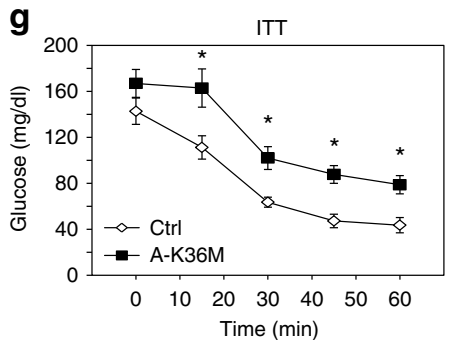
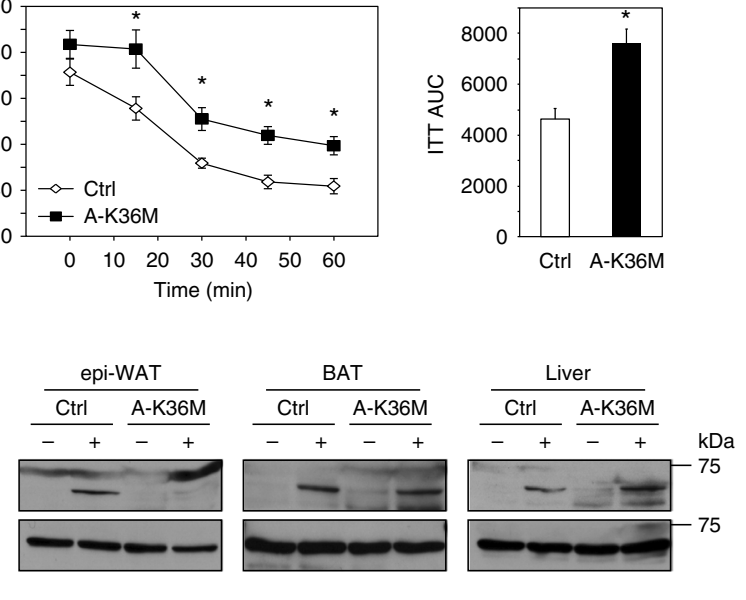

Fig. 6 Adipose-selective expression of H3.3K36M causes insulin resistance in WAT. Eight-week-old to 10-week-old male Ctrl and A-K36M mice ( $n=6$ per group) were fed with regular diet. a H\&E staining of ing-WAT (upper panels) and epi-WAT (lower panels). Scale bar $=100 \mu \mathrm{m}$. Average sizes of adipocytes in ing-WAT and epi-WAT are shown on the right. Adipocyte size was calculated using ImageJ. $\mathbf{b}$ H\&E staining of the liver. Scale bar $=100 \mu m$. Triglyceride content in the liver is shown on the right. c Serum leptin (left) and adiponectin (right) levels. d Serum levels of free fatty acid (FFA), triglyceride, and cholesterol. e qRT-PCR analysis of adipogenesis, lipolysis, insulin sensitivity, and adipokine genes in ing-WAT and epi-WAT. f Glucose tolerance test (GTT). Area under the curve (AUC) is shown on the right. $\mathbf{g}$ Insulin tolerance test (ITT). AUC is shown on the right. $\mathbf{h}$ Fed or fasted blood glucose levels. i Serum insulin levels in the random-fed status. $\mathbf{j}$ Western blot of phosphorylated Akt at Serine 473 (p-Akt) and total Akt in protein extracts of ing-WAT, epi-WAT, BAT, and liver. All values in Fig. 6 are presented as means \pm SEM. Statistical comparison between groups was performed using Student's $t$ test. ${ }^{*} p<0.05$ 
a

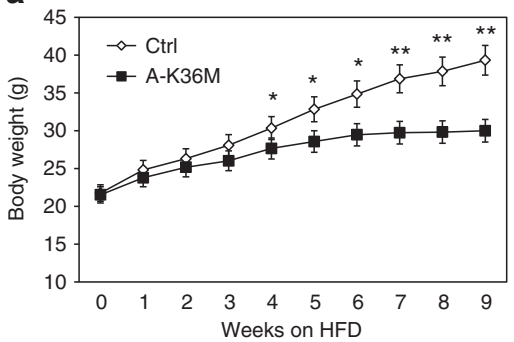

b

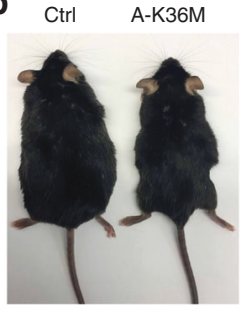

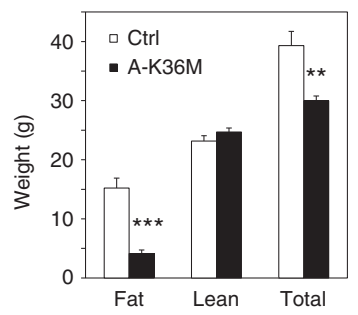

C

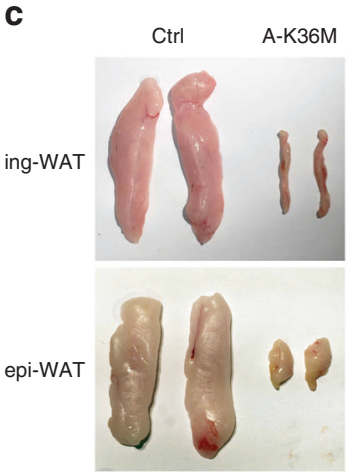

Liver
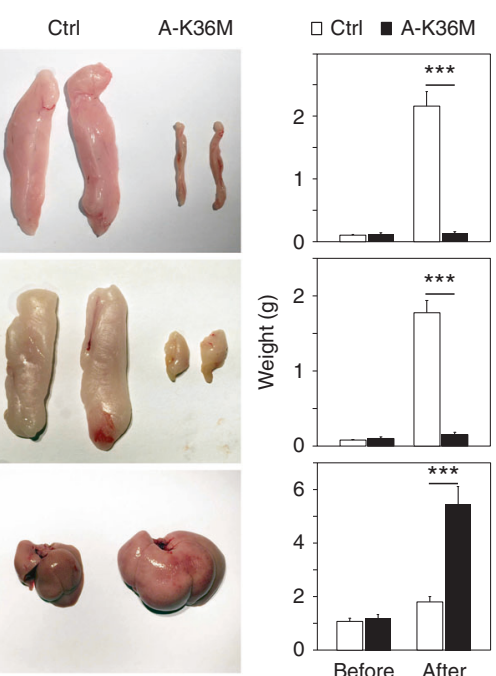

H\&E

Ctrl

A-K36M
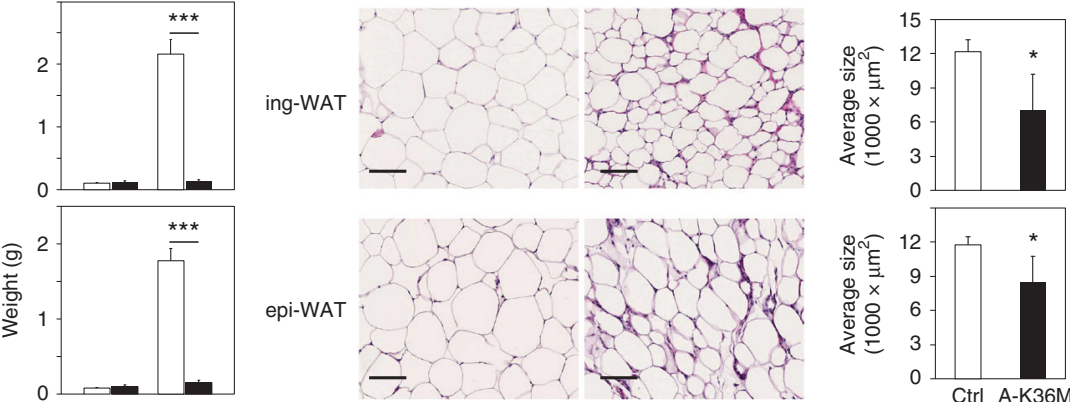

Epi-WAT
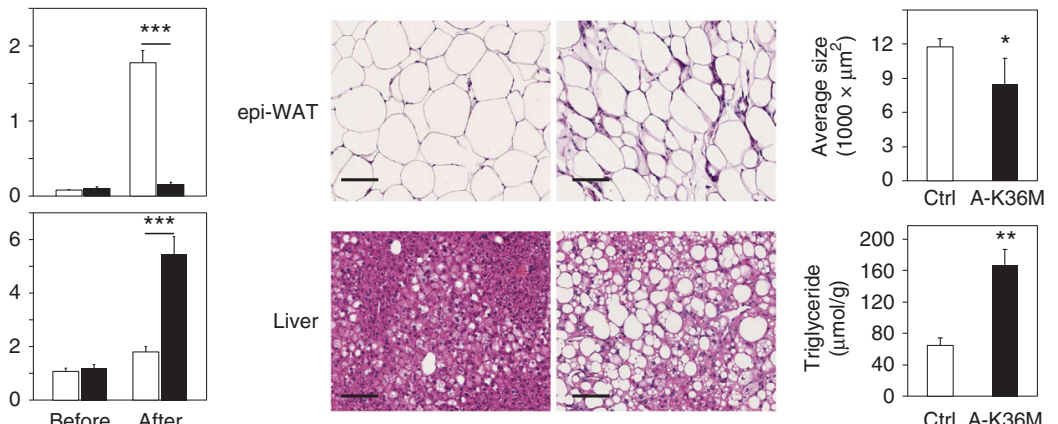

e
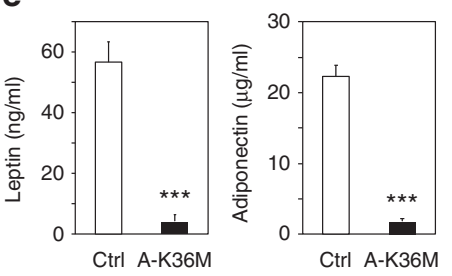

i

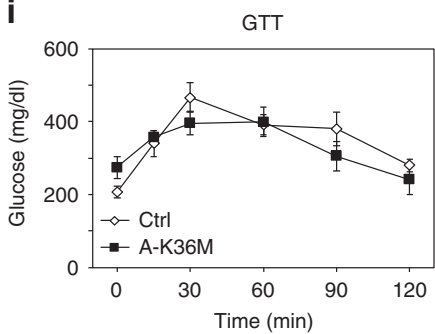

$\mathbf{f}$
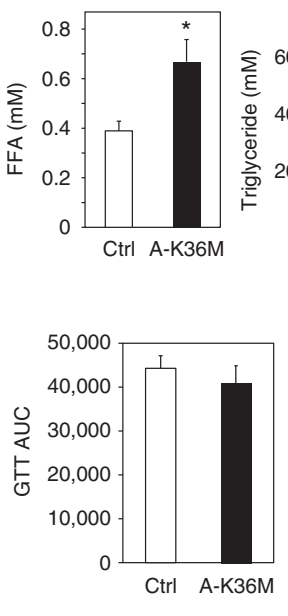
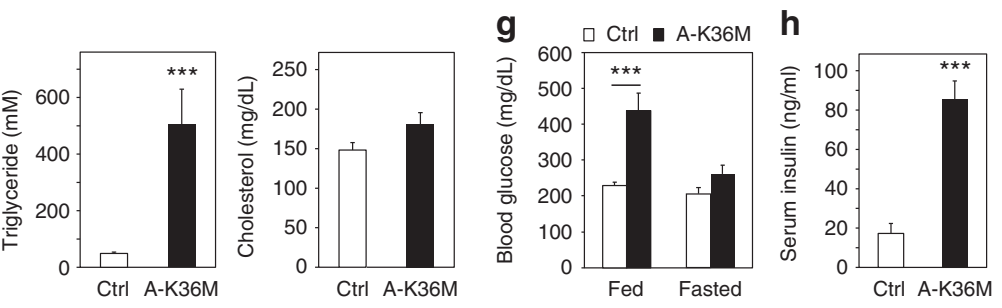

j

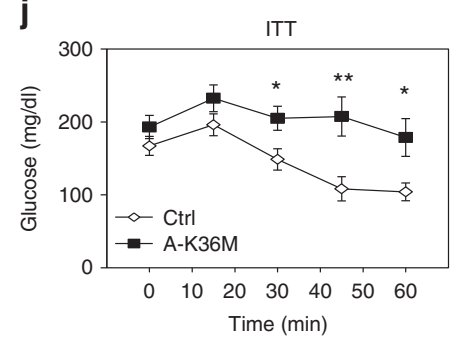

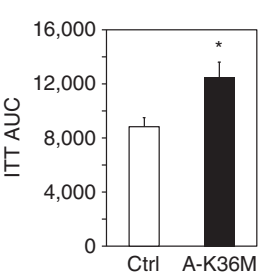

Fig. 7 Mice with adipose-selective expression of H3.3K36M are resistant to HFD-induced WAT expansion. Male Ctrl and A-K36M mice ( $n=6$ per group) were fed with high fat diet (HFD) for 10 to 11 weeks starting from the 9th week of age. a Body weight during HFD feeding. $\mathbf{b}$ Representative picture of mice after HFD feeding (left). Fat mass, lean mass, and total body weight were measured by MRI (right). c Representative pictures of ing-WAT, epi-WAT, and liver (left panels). Average tissue weights are shown in right panels. before: tissue weights of 8-week-old mice fed with regular diet; after: tissue weights of mice after HFD. $\mathbf{d}$ H\&E staining of ing-WAT, epi-WAT, and liver (left panels). Scale bar $=100 \mu \mathrm{m}$. Average sizes of adipocytes in ing-WAT and epi-WAT, and the liver triglyceride contents are shown on the right. e Serum leptin (left) and adiponectin (right) levels. f Serum levels of FFA, triglyceride, and cholesterol. $\mathbf{g}$ Fed or fasted blood glucose levels. h Serum insulin levels. i GTT. AUC is shown on the right. $\mathbf{j}$ ITT. AUC is shown on the right. All values are presented as mean \pm SEM. Statistical comparison between groups was performed using Student's $t$ test. ${ }^{\star} p<0.05$, ${ }^{\star \star} p<0.01$, and ${ }^{\star \star \star} p<0.005$

fat mass in the A-K36M mice, levels of adiponectin and leptin were much lower in A-K36M mice than in Ctrl (Fig. 7e). The FFA and triglyceride levels were much higher in the serum of A-K36M mice than Ctrl, but the cholesterol levels were similar (Fig. 7f). The blood glucose and serum insulin levels were much higher in
A-K36M mice after HFD (Fig. 7g, h). Although the A-K36M mice showed similar levels of glucose intolerance to Ctrl (Fig. 7i), they were more insulin resistant (Fig. $7 \mathrm{j}$ ). The expression of genes associated with adipogenesis, lipolysis, insulin sensitivity, and adipokines decreased in WAT of A-K36M mice (Supplementary 


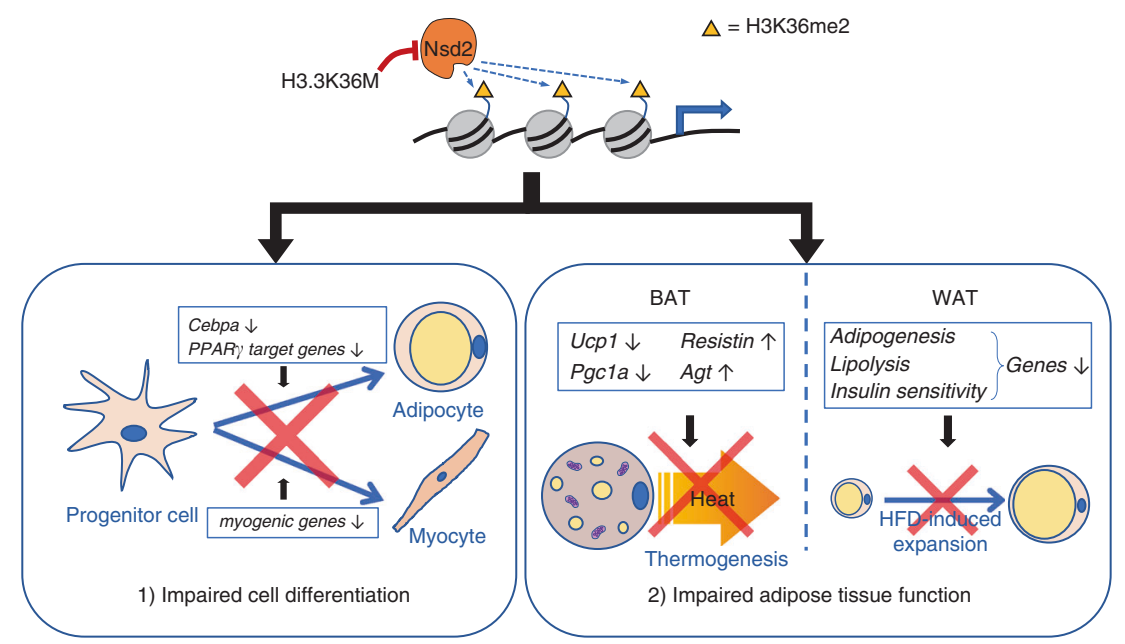

Fig. 8 A schematic model on the role of Nsd2-mediated H3K36me2 in adipose tissue development and function. In progenitor cells, depletion of Nsd2mediated H3K36me2 by H3.3K36M leads to defects in adipose tissue development (adipogenesis) and muscle development (myogenesis). In mature adipocytes, depletion of $\mathrm{H} 3 \mathrm{~K} 36 \mathrm{me} 2$ by $\mathrm{H} 3.3 \mathrm{~K} 36 \mathrm{M}$ reprograms functional gene expression, impairing brown and white adipose tissue functions

Fig. 12d). Together, these data indicate that under HFD, mice with adipose tissue-selective expression of H3.3K36M develop severe lipodystrophy associated with hyperlipidemia, insulin resistance, and diabetes. Interestingly, HFD feeding slightly decreased H3K36me2 levels in adipose tissues of Ctrl mice (Supplementary Fig. 13).

\section{Discussion}

We show that depletion of $\mathrm{H} 3 \mathrm{~K} 36$ methylation by $\mathrm{H} 3.3 \mathrm{~K} 36 \mathrm{M}$ inhibits adipogenesis by increasing $\mathrm{H} 3 \mathrm{~K} 27 \mathrm{me} 3$ to prevent the induction of adipogenic gene Cebpa and other PPAR $\gamma$ target genes. H3.3K36M achieves these effects by inhibiting H3K36 dimethyltransferase Nsd2. Through generation of LSL-K36M;Myf5Cre mice, we demonstrate that $\mathrm{H} 3.3 \mathrm{~K} 36 \mathrm{M}$ expression in progenitor cells impairs adipose tissue development. Through generation of A-K36M mice, we show that depletion of $\mathrm{H} 3 \mathrm{~K} 36$ methylation by $\mathrm{H} 3.3 \mathrm{~K} 36 \mathrm{M}$ in adipocytes reprograms gene expression profile and hinders normal functions of BAT and WAT. Together, our data suggest that Nsd2-mediated H3K36 methylation plays a critical role in regulating adipogenesis and adipose tissue function. A schematic in Fig. 8, reflecting our consistent data from in vitro and in vivo experiments, illustrates our conclusion that $\mathrm{H} 3 \mathrm{~K} 36$ methylation is important for adipose tissue development and function. In progenitor cells, depletion of H3K36 methylation by H3.3K36M leads to defects in adipose tissue development. In mature adipocytes, depletion of $\mathrm{H} 3 \mathrm{~K} 36$ methylation by $\mathrm{H} 3.3 \mathrm{~K} 36 \mathrm{M}$ reprograms functional gene expression, impairing BAT and WAT functions.

A recent paper reported that $\mathrm{H} 3 \mathrm{~K} 36 \mathrm{M}$ decreases $\mathrm{H} 3 \mathrm{~K} 27 \mathrm{me} 3$ levels on mesenchymal stem cell (MSC) genes, which allows MSC gene expression to inhibit cell differentiation including osteogenesis and adipogenesis ${ }^{29}$. Using preadipocyte differentiation as the model system, we show two mechanisms by which H3K36M inhibits adipogenesis. First, H3K36M increases H3K27me3 levels on the gene locus encoding a master adipogenic transcription factor $\mathrm{C} / \mathrm{EBPa}$, which prevents $\mathrm{C} / \mathrm{EBPa}$ expression. Second, $\mathrm{H} 3 \mathrm{~K} 36 \mathrm{M}$ targets Nsd2 to inhibit ligand-induced expression of target genes of PPAR $\gamma$, the other master regulator of adipogenesis. In cell culture, we show that ectopic expression of $\mathrm{H} 3.3 \mathrm{~K} 36 \mathrm{M}$ inhibits adipogenesis of both white and brown preadipocytes, as well as $\mathrm{C} / \mathrm{EBP} \alpha$-stimulated and PPAR $\gamma$-stimulated adipogenesis. Furthermore, by expressing $\mathrm{H} 3.3 \mathrm{~K} 36 \mathrm{M}$ in progenitor cells of adipocytes, we show that $\mathrm{H} 3 \mathrm{~K} 36$ methylation is required for adipogenesis in vivo. Finally, by expressing H3K36M in mature adipocytes, we show that $\mathrm{H} 3 \mathrm{~K} 36$ methylation is important for adipose tissue function in mice.

We show in Supplementary Fig. $1 \mathrm{a}-\mathrm{c}$ that H3.1K36M and H3.3K36M have similar effects on H3K36me2 levels, adipogenesis, and adipogenic gene expression. These results are consistent with a previous study ${ }^{29}$, which reported different distributions of $\mathrm{H} 3.1 \mathrm{~K} 36 \mathrm{M}$ and $\mathrm{H} 3.3 \mathrm{~K} 36 \mathrm{M}$ but similarly altered gene expression profiles between $\mathrm{H} 3.1 \mathrm{~K} 36 \mathrm{M}$-expressing and H3.3K36M-expressing MSCs. Together, these results suggest a substantial transeffect of $\mathrm{H} 3 \mathrm{~K} 36 \mathrm{M}$, but we cannot rule out the potential involvement of a cis-effect of H3K36M. It has been shown previously that $\mathrm{H} 3.3 \mathrm{~K} 36 \mathrm{M}$ incorporated in nucleosomes reduced $\mathrm{H} 3 \mathrm{~K} 36 \mathrm{me} 2$ and H3K36me 3 levels locally ${ }^{30}$, suggesting a cis-effect. However, since the expression levels of H3.3K $36 \mathrm{M}$ were much lower than that of endogenous $\mathrm{H} 3$, the cis-effect of $\mathrm{H} 3 \mathrm{~K} 36 \mathrm{M}$ on chromatin is unlikely to play a major role in the cells used in this study.

H3.3K36M depletes H3K36me2 but only mildly decreases $\mathrm{H} 3 \mathrm{~K} 36 \mathrm{me} 3$ in preadipocytes, suggesting that $\mathrm{H} 3 \mathrm{~K} 36$ dimethyltransferases may be the target of H3.3K36M. Four lines of evidence support that Nsd2 is the major target of $\mathrm{H} 3.3 \mathrm{~K} 36 \mathrm{M}$ in adipogenesis. First, knockdown screening results showed that depletion of the major H3K36 di-methyltransferase Nsd2, but not the major H3K36 tri-methyltransferase Setd2, leads to defects in adipogenesis. Second, Nsd2 depletion caused defects in C/EBPastimulated or PPAR $\gamma$-stimulated adipogenesis and impaired ligand-induced PPAR $\gamma$ target gene expression. Third, Nsd2 depletion caused an increase in $\mathrm{H} 3 \mathrm{~K} 27 \mathrm{me} 3$, which repressed $\mathrm{C} /$ EBPa and other PPAR $\gamma$ target genes. Fourth, Nsd2 enzymatic activity is required for adipogenesis. Thus, depletion of $\mathrm{Nsd} 2$ phenocopies ectopic $\mathrm{H} 3.3 \mathrm{~K} 36 \mathrm{M}$ expression in adipogenesis. These data indicate that $\mathrm{H} 3.3 \mathrm{~K} 36 \mathrm{M}$ targets $\mathrm{Nsd} 2$ to deplete $\mathrm{H} 3 \mathrm{~K} 36 \mathrm{me} 2$ and inhibit adipogenesis in preadipocytes. Although both Nsd1 and Nsd2 are methyltransferases for $\mathrm{H} 3 \mathrm{~K} 36 \mathrm{me} 2{ }^{15}$, $\mathrm{Nsd} 2 \mathrm{KD}$ has more significant effects on $\mathrm{H} 3 \mathrm{~K} 36 \mathrm{me} 2$ levels around gene loci of Cebpa, Lpl, and Cd36 (Supplementary Fig. 6b), suggesting that Nsd2-mediated $\mathrm{H} 3 \mathrm{~K} 36 \mathrm{me} 2$ plays a major role in regulating adipogenic gene expression.

Since the Fabp4 (aP2) promoter is also active in macrophages, we have investigated the contributions of macrophages and inflammation to the phenotype of A-K36M mice. As shown in 
Supplementary Fig. 14a, significant macrophage infiltration is detected in the WAT of A-K36M mice. Consistently, RNA-Seq analyses revealed increased expression of inflammatory response genes such as Emr1 (F4/80), Ccl2, Tnf, and IL-6 in epi-WAT of AK36M mice (Supplementary Fig. 14b). However, RNA-Seq analyses showed that $\mathrm{H} 3.3 \mathrm{~K} 36 \mathrm{M}$ mildly decreases the expression of Emr1, Ccl2, Tnf, and IL-6 in RAW264.7 macrophages in cell culture (Supplementary Fig. 14c, d). Together, these data suggest that while macrophage infiltration and inflammation in WAT likely contribute to the phenotype of A-K36M mice, the inflammation is not directly caused by $\mathrm{H} 3.3 \mathrm{~K} 36 \mathrm{M}$ expression in macrophages. Macrophage infiltration and inflammation in WAT have been reported in other lipodystrophic mouse models ${ }^{31}$.

\section{Methods}

Plasmids and antibodies. Retroviral plasmids expressing WT or mutants of histone H3.1 or H3.3 including pQCXIP-H3.1-FLAG, pQCXIP-H3.1K36M-FLAG, pQCXIP-H3.3-FLAG, and pQCXIP-H3.3K36M-FLAG were described ${ }^{23}$. pMSCVhygro-PPAR $\gamma 2$, pWZLhygro-C/EBP $\alpha$, and pMSCVpuro-MyoD have been described $^{13}$. The full-length human NSD2 with a C-terminal FLAG tag was from Origene (RC221350) and was cloned into pMSCVhygro to generate pMSCVhygroNSD2-FLAG. The Y1092A/Y1179A and H1142G/Y1179A mutants of NSD2 were generated by PCR mutagenesis. Lentiviral short hairpin RNA plasmids targeting Ctrl (SHC002), mouse Nsd1 (TRCN0000441097 and TRCN0000123379), Nsd2 (TRCN0000253039 and TRCN0000226296), and Setd2 (TRCN0000238537 and TRCN0000238535) genes were purchased from Sigma. For CRISPR/Cas9-mediated knockout of Nsd2, guide RNA (gRNA) was designed according to CRISPR.mit.edu. The gRNA sequence for Nsd2 is 5'-GCAATTGGTCCCCCACATAA-3'. pSpCas9 (BB)-2A-Puro (PX459) was from Addgene (48139) $)^{32}$. gRNA was cloned into PX459 to generate a gRNA-Cas9-2A-Puro single plasmid construct. All plasmids were confirmed by DNA sequencing.

Anti-NSD2 antibody (13-0002) was from EpiCypher. Anti-C/EBPa (sc-61x) and anti-PPAR $\gamma$ (sc-7196x) were from Santa Cruz Biotechnology. Anti-F4/80 (MAB5580) was from R\&D Systems. Anti-myosin (MF20) was from Developmental Studies Hybridoma Bank. Anti-RbBP5 (AA300-109A) was from Bethyl Laboratories. Rabbit IgG (I-5006), anti- $\beta$-actin (A2228), and anti-FLAG (F3165) were from Sigma. Anti-histone H3 (ab1791) and anti-H3K36me3 (ab9050) were from Abcam. Anti-H3K36me2 (07-369) and anti-H3K27me3 (07-449) were from Millipore. Anti-Akt (9272) and anti-phosphorylated-Akt (Ser 473) (4051) were from Cell Signaling Technology. Whole-cell lysates were prepared for Western blot of Nsd2, C/EBPa, PPAR $\gamma$, Ucp1, and the loading Ctrl RbBP5 and actin. Acid-extracted histones were prepared for Western blot of histone methylations. For Western blot, all antibodies were diluted to $1 \mu \mathrm{g} \mathrm{ml} l^{-1}$. Uncropped blots are available in the Supplementary Fig. 15.

Adipogenesis and myogenesis assays. Primary brown preadipocytes were isolated from BAT of newborn WT, LSL-K36M;Cre-ER or A-K36M mice. Cells were immortalized by infecting with retroviruses expressing SV40 $\mathrm{T}^{13}$. 3T3-L1 cells were from Daniel Lane. Adipogenesis of immortalized brown preadipocytes and the 3T3-L1 white preadipocyte cell line were induced by adding induction medium (Dulbecco's modified Eagle's medium (DMEM) supplemented with $10 \%$ fetal bovine serum (FBS), $0.02 \mu \mathrm{M}$ insulin, $1 \mathrm{nM} \mathrm{T3}, 0.5 \mathrm{mM}$ isobutylmethylxanthine, 2 $\mu \mathrm{g} \mathrm{ml}^{-1}$ dexamethasone, and $0.125 \mathrm{mM}$ indomethacin) ${ }^{12}$. After 2 days of induction, the culture medium was changed to DMEM supplemented with FBS, insulin, and T3 only. PPAR $\gamma$-stimulated or C/EBP $\alpha$-stimulated adipogenesis was done by infecting cells with retroviruses expressing PPAR $\gamma$ or C/EBPa before induction ${ }^{33}$.

C2C12 myoblasts were purchased from ATCC and cultured in growth medium (DMEM supplemented with 15\% FBS). Myogenesis was induced by changing growth medium to differentiation medium (DMEM supplemented with $2 \%$ horse serum) when cells were confluent ${ }^{8}$.

Quantitative reverse transcription-PCR. Total RNA was extracted using TRIzol (Invitrogen) and reverse transcribed using ProtoScript II first-strand cDNA synthesis kit (NEB), following the manufacturer's instructions. Quantitative reverse transcription-PCR (qRT-PCR) of $N s d 2$ was done using SYBR green primers: forward, 5'-GGCCAGAACAAGCTCTTACAA-3' and reverse, 5'

TGTGGGCTCCCATAAAAGCTC- $3^{\prime}$. Other SYBR green primers for qRT-PCR are listed in the Supplementary Table 1.

Histology and immunofluorescence. E18.5 embryos were isolated by Cesarean section. P0 pups were collected after birth. Samples were fixed in $4 \%$ paraformaldehyde after isolation, dehydrated in a methanol series, and embedded in paraffin. Paraffin sections were stained with routine H\&E or subjected to immunohistochemistry using anti-myosin (MF20; Developmental Studies Hybridoma Bank) and anti-UCP1 (ab10983; Abcam) antibodies were diluted to $10 \mu \mathrm{g} \mathrm{ml}^{-18}$.
ChIP-Seq and RNA-Seq. For ChIP-Seq analysis, crosslinking of cells was done by adding $2 \%$ formaldehyde for $10 \mathrm{~min}$ at room temperature, and stopped by adding $125 \mathrm{mM}$ glycine. The cells were washed twice with ice-cold phosphate-buffered saline. A total of $2 \times 10^{7}$ cells were collected in $10 \mathrm{ml}$ Farnham lysis buffer $(5 \mathrm{mM}$ PIPES, pH 8.0, $85 \mathrm{mM} \mathrm{KCl}, 0.5 \% \mathrm{NP}-40$, supplemented with protease inhibitors). After centrifuging at $4000 \times g$ for $5 \mathrm{~min}$ at $4^{\circ} \mathrm{C}$, cell pellet was washed with $10 \mathrm{ml}$ Farnham lysis buffer. The nuclear pellet was resuspended in $1 \mathrm{ml}$ TE buffer with protease inhibitors and sonicated for $17 \mathrm{~min}$ ( $30 \mathrm{~s}$ on/off cycle). Detergents were added to the lysates to make $1 \times$ RIPA buffer ( $10 \mathrm{mM}$ Tris-Cl, $\mathrm{pH}$ 7.7, $1 \mathrm{mM}$ EDTA $0.1 \%$ sodium dodecyl sulfate (SDS), $0.1 \%$ sodium deoxycholate (Na-DOC), $1 \%$ Triton X-100) and centrifuged at $13,000 \times g$ for $15 \mathrm{~min}$ at $4{ }^{\circ} \mathrm{C}$ to remove debris. Eight micrograms of antibodies were pre-incubated with $50 \mu$ l Dynabeads Protein A (Life Technologies) overnight at $4^{\circ} \mathrm{C}$. For each ChIP, antibody-beads complex was added to chromatin and incubated overnight at $4{ }^{\circ} \mathrm{C}$. The beads were washed with RIPA buffer twice, high-salt-RIPA buffer (RIPA containing $0.3 \mathrm{M} \mathrm{NaCl}$ ) twice, $\mathrm{LiCl}$ buffer ( $50 \mathrm{mM}$ Tris-Cl, pH 7.5, $250 \mathrm{mM} \mathrm{LiCl}, 0.5 \% \mathrm{NP}-40,0.5 \% \mathrm{Na}-$ DOC) twice and TE buffer once. DNA was eluted and reverse-crosslinked in $200 \mu \mathrm{l}$ elution buffer ( $1 \% \mathrm{SDS}, 0.1 \mathrm{M} \mathrm{NaHCO}_{3}$, and supplemented with $20 \mu \mathrm{g}$ proteinase $\mathrm{K}$ ) overnight at $65^{\circ} \mathrm{C}$, and purified by QIAquick PCR Purification Kit (Qiagen) $)^{8,34}$ ChIP SYBR Green primers were designed at indicated distance to the transcription start site of Cebpa. The sequences of primers are listed in Supplementary Table 1.

For RNA-Seq, mRNAs were purified using Dynabeads mRNA Purification Kit (Invitrogen), and then double-stranded cDNAs were synthesized by SuperScript Double-Stranded cDNA Synthesis Kit (Invitrogen). All ChIP-Seq and RNA-Seq sequencing libraries were constructed using NEBNext Ultra II DNA Library Prep Kit for Illumina (NEB), following the manufacturer's instructions. All ChIP-Seq and RNA-Seq samples were sequenced on the Illumina HiSeq $2500^{35}$

ChIP-Seq data were analyzed by SICER ${ }^{36}$. Raw reads were mapped to the mouse genome (mm9). H3K36me2 or H3K27me3 signal intensity at each nucleotide was calculated as read coverage, followed by scaling normalization to ensure that the average intensity across the whole genome equals to 1 for each sample. The input intensity was subtracted from the ChIP signal based on a Poisson model ${ }^{17}$. Then, H3K36me2 or H3K27me3 signal intensity was further normalized with global H3K36me2 or H3K27me3 levels measured by Western blot to justify the global changes of these histone methylations. ChIP-Seq and RNA-Seq datasets were deposited in the GEO database (accession no. GSE83793).

Generation of transgenic mice. To generate LSL-K36M transgenic mice, fulllength $\mathrm{H} 3.3$ with a K36M point mutation and a C-terminal FLAG tag was fused downstream of CAG promoter with a loxP-STOP-loxP cassette in the middle as described previously ${ }^{37}$. To generate A-K36M transgenic mice, FLAG-tagged H3.3K36M was fused downstream of the $7.9 \mathrm{~kb}$ Fabp4 (aP2) promoter described previously ${ }^{27}$. The transgenic DNA fragment was gel purified and injected into zygotes harvested from C57BL/6J mice. Founder mice were identified by genotyping and Western blot using an anti-FLAG antibody. LSL-K36M mice were crossed with Myf5-Cre (Jackson no. 007893, C57BL/6J and 129S4/SvJaeSor mixed background) or Cre-ER (Jackson no. 008463) to generate LSL-K36M;Myf5-Cre or LSL-K36M;Cre-ER mice. Animals were maintained on a $12 \mathrm{~h}$ light/dark cycle (6:00 a.m. $/ 6: 00$ p.m.) and standard pellet diet (NIH-07, 15 kcal\% fat, Envigo Inc.), unless otherwise indicated. HFD D12492 (Research Diet) consisted of $59.4 \mathrm{kcal} \%$ fat, 16.2 $\mathrm{kcal} \%$ protein, and $24.5 \mathrm{kcal} \%$ carbohydrates. Animals were not randomized and the researchers were not blinded during the experiment and when assessing the outcome. No animals were excluded from the analysis. All mouse experiments were performed in accordance with the NIH Guide for the Care and Use of Laboratory Animals and approved by the Animal Care and Use Committee of NIDDK, NIH.

Body composition and metabolic studies. Body composition was measured with the EchoMRI 3-in-1 analyzer (Echo Medical Systems). Food intake, $\mathrm{O}_{2}$ consumption, and $\mathrm{CO}_{2}$ production were measured at $22^{\circ} \mathrm{C}$ over a $24 \mathrm{~h}$ period in a CLAMS system (Columbus Instruments Inc.; $2.5 \mathrm{~L}$ chambers with plastic floors, using $0.6 \mathrm{~L} \mathrm{~min}^{-1}$ flow rate, one mouse per chamber) after a $48 \mathrm{~h}$ adaptation period. Motor activity (total and ambulatory) was simultaneously measured by infrared beam interruption. Resting $\mathrm{O}_{2}$ consumption was calculated as the mean of the points with fewer than six ambulating beam breaks per minute. CL316,243 (Sigma-Aldrich; $0.01 \mathrm{mg} \mathrm{kg}^{-1}$ intraperitoneally (i.p.)) or saline vehicle was administered and $\mathrm{O}_{2}$ consumption was measured at $30^{\circ} \mathrm{C}$ from 1 to $4 \mathrm{~h}$ after injection To measure the cumulative body composition, food intake, and energy expenditure, mice were single-housed and allowed to acclimate for 1 week before measurement during the subsequent 8 weeks ( 3 weeks fed with $\mathrm{RD}$, followed by 5 weeks fed with HFD). Energy expenditure was calculated by energy balance technique ${ }^{38}$.

Cold tolerance test. To test mouse cold tolerance, mice were individually caged and exposed to an ambient temperature of $4{ }^{\circ} \mathrm{C}$. Core body temperature was measured using a rectal thermometer (TH-5, Braintree Scientific) before and hourly after cold exposure.

GTTs and ITTs. For GTTs, $4 \mathrm{~h}$ fasted mice received glucose $\left(1 \mathrm{~g} \mathrm{~kg}^{-1}\right.$ i.p.). For ITTs, mice were fasted for $4 \mathrm{~h}$ before administration of insulin (Humulin, $0.75 \mathrm{mI}$ 
$\mathrm{U} \mathrm{g}^{-1}$, i.p., Eli Lilly). For both tests, glucose level was measured from the tail vein at indicated time points with a glucometer (Contour, Bayer).

In vivo lipolysis. Randomly fed mice were injected i.p. saline or CL316,243 (Sigma, $0.1 \mathrm{mg} \mathrm{kg}^{-1}$ ) in a cross-over manner and blood was collected 20 min later. Plasma FFA level was measured with reagents from Roche Diagnostics.

Serum and tissue chemistries. Glucose was measured with a glucometer (Bayer). FFA, triglyceride, and total cholesterol were measured with reagents from Roche Diagnostics GmbH, Pointe Scientific Inc., and Thermo Scientific, respectively. Adiponectin, insulin, and leptin were measured by enzyme-linked immunosorbent assay from ALPCO, CrystalChem, and RD Systems, respectively. Liver triglyceride was extracted using phenol-chloroform (3:1) and measured by a kit from Pointe Scientific Inc.

In vivo insulin signaling assay. In vivo insulin signaling in the adipose tissues and liver was measured by AKT phosphorylation ${ }^{39}$. Briefly, mice were fasted for $24 \mathrm{~h}$ before insulin injection. Anesthetized mice were surgically operated, and one side of the BAT, ing-WAT, and epi-WAT and a piece of the liver were excised and snap-frozen in liquid nitrogen for use as an untreated Ctrl. Three minutes after injection via the inferior vena cava with $1 \mathrm{U} \mathrm{kg}^{-1}$ of human insulin (Eli Lilly), the other side of the BAT, ing-WAT, and epi-WAT and a piece of the liver were snapfrozen for subsequent protein extraction and Western blot analysis.

Statistics. Results are expressed as means \pm SEM (standard error of the mean). Means of continuous outcome variables were tested with two-tailed Student's $t$ test. $P$ values $<0.05$ were considered statistically significant.

Data availability. All datasets described in the paper have been deposited in NCBI Gene Expression Omnibus under accession number GSE83793. We declare that the data supporting the findings of this study are available within the article and its Supplementary Information files, or available from the authors upon request.

Received: 14 July 2017 Accepted: 5 April 2018

Published online: 04 May 2018

\section{References}

1. Rosen, E. D. \& Spiegelman, B. M. Adipocytes as regulators of energy balance and glucose homeostasis. Nature 444, 847-853 (2006).

2. Cannon, B. \& Nedergaard, J. Respiratory and thermogenic capacities of cells and mitochondria from brown and white adipose tissue. Methods Mol. Biol. 155, 295-303 (2001).

3. Tseng, Y. H., Cypess, A. M. \& Kahn, C. R. Cellular bioenergetics as a target for obesity therapy. Nat. Rev. Drug. Discov. 9, 465-481 (2010).

4. Cannon, B. \& Nedergaard, J. Brown adipose tissue: function and physiological significance. Physiol. Rev. 84, 277-359 (2004)

5. Rosen, E. D. \& MacDougald, O. A. Adipocyte differentiation from the inside out. Nat. Rev. Mol. Cell. Biol. 7, 885-896 (2006).

6. Cristancho, A. G. \& Lazar, M. A. Forming functional fat: a growing understanding of adipocyte differentiation. Nat. Rev. Mol. Cell. Biol. 12 722-734 (2011).

7. Rosen, E. D. et al. C/EBPalpha induces adipogenesis through PPARgamma: a unified pathway. Genes Dev. 16, 22-26 (2002).

8. Lee, J. E. et al. H3K4 mono- and di-methyltransferase MLL4 is required for enhancer activation during cell differentiation. eLife 2, e01503 (2013).

9. Lee, J. E. \& Ge, K. Transcriptional and epigenetic regulation of PPAR gamma expression during adipogenesis. Cell Biosci. 4, 29 (2014).

10. Loft, A., Forss, I. \& Mandrup, S. Genome-wide insights into the development and function of thermogenic adipocytes. Trends Endocrinol. Metab. 28, 104-120 (2017).

11. Ge, K. Epigenetic regulation of adipogenesis by histone methylation. $B B A$ Gene Regul. Mech. 1819, 727-732 (2012).

12. Wang, L. et al. Histone $\mathrm{H} 3 \mathrm{~K} 9$ methyltransferase G9a represses PPAR[gamma] expression and adipogenesis. EMBO J. 32, 45-59 (2013).

13. Wang, L., Jin, Q., Lee, J. E., Su, I. H. \& Ge, K. Histone H3K27 methyltransferase Ezh2 represses Wnt genes to facilitate adipogenesis. Proc Natl. Acad. Sci. USA 107, 7317-7322 (2010).

14. Duteil, D. et al. Lsd1 ablation triggers metabolic reprogramming of brown adipose tissue. Cell Rep. 17, 1008-1021 (2016).

15. Wagner, E. J. \& Carpenter, P. B. Understanding the language of Lys36 methylation at histone H3. Nat. Rev. Mol. Cell. Biol. 13, 115-126 (2012).
16. Edmunds, J. W., Mahadevan, L. C. \& Clayton, A. L. Dynamic histone H3 methylation during gene induction: $\mathrm{HYPB} / \mathrm{Setd} 2$ mediates all $\mathrm{H} 3 \mathrm{~K} 36$ trimethylation. EMBO J. 27, 406-420 (2008).

17. Kuo, A. J. et al. NSD2 links dimethylation of histone $\mathrm{H} 3$ at lysine 36 to oncogenic programming. Mol. Cell 44, 609-620 (2011).

18. Li, Y. et al. The target of the NSD family of histone lysine methyltransferases depends on the nature of the substrate. J. Biol. Chem. 284, 34283-34295 (2009).

19. Popovic, R. et al. Histone methyltransferase MMSET/NSD2 alters EZH2 binding and reprograms the myeloma epigenome through global and focal changes in H3K36 and H3K27 methylation. PLoS Genet. 10, e1004566 (2014).

20. Yuan, W. et al. H3K36 methylation antagonizes PRC2-mediated H3K27 methylation. J. Biol. Chem. 286, 7983-7989 (2011).

21. Behjati, S. et al. Distinct H3F3A and H3F3B driver mutations define chondroblastoma and giant cell tumor of bone. Nat. Genet. 45, 1479-1482 (2013).

22. Lewis, P. W. et al. Inhibition of PRC2 activity by a gain-of-function H3 mutation found in pediatric glioblastoma. Science 340, 857-861 (2013).

23. Chan, K. M., Han, J., Fang, D., Gan, H. \& Zhang, Z. A lesson learned from the H3.3K27M mutation found in pediatric glioma: a new approach to the study of the function of histone modifications in vivo? Cell Cycle 12, 2546-2552 (2013).

24. Subramanian, A. et al. Gene set enrichment analysis: a knowledge-based approach for interpreting genome-wide expression profiles. Proc. Natl. Acad. Sci. USA 102, 15545-15550 (2005).

25. Nimura, K. et al. A histone $\mathrm{H} 3$ lysine 36 trimethyltransferase links Nkx2-5 to Wolf-Hirschhorn syndrome. Nature 460, 287-291 (2009).

26. Seale, P. et al. PRDM16 controls a brown fat/skeletal muscle switch. Nature 454, 961 (2008).

27. Moitra, J. et al. Life without white fat: a transgenic mouse. Gene Dev. 12, 3168-3181 (1998).

28. Collins, S. \& Surwit, R. S. The beta-adrenergic receptors and the control of adipose tissue metabolism and thermogenesis. Recent Prog. Horm. Res. 56, 309-328 (2001)

29. Lu, C. et al. Histone $\mathrm{H} 3 \mathrm{~K} 36$ mutations promote sarcomagenesis through altered histone methylation landscape. Science 352, 844-849 (2016).

30. Fang, D. et al. The histone H3.3K36M mutation reprograms the epigenome of chondroblastomas. Science 352, 1344-1348 (2016).

31. He, W. et al. Adipose-specific peroxisome proliferator-activated receptor gamma knockout causes insulin resistance in fat and liver but not in muscle. Proc. Natl. Acad. Sci. USA 100, 15712-15717 (2003).

32. Ran, F. A. et al. Genome engineering using the CRISPR-Cas9 system. Nat. Protoc. 8, 2281-2308 (2013).

33. Ge, K. et al. Transcription coactivator TRAP220 is required for PPAR gamma 2-stimulated adipogenesis. Nature 417, 563-567 (2002).

34. Lai, B. et al. MLL3/MLL4 are required for CBP/p300 binding on enhancers and super-enhancer formation in brown adipogenesis. Nucleic Acids Res. 45, 6388-6403 (2017)

35. Cho, Y. W. et al. Histone methylation regulator PTIP is required for PPARgamma and C/EBPalpha expression and adipogenesis. Cell Metab. 10, 27-39 (2009).

36. Zang, C. et al. A clustering approach for identification of enriched domains from histone modification ChIP-Seq data. Bioinformatics 25, 1952-1958 (2009).

37. Bradley, S. V. et al. Degenerative phenotypes caused by the combined deficiency of murine HIP1 and HIP1r are rescued by human HIP1. Hum. Mol. Genet. 16, 1279-1292 (2007).

38. Ravussin, Y., Gutman, R., LeDuc, C. A. \& Leibel, R. L. Estimating energy expenditure in mice using an energy balance technique. Int. J. Obes. 37, 399-403 (2013).

39. Wang, Q. et al. Abrogation of hepatic ATP-citrate lyase protects against fatty liver and ameliorates hyperglycemia in leptin receptor-deficient mice. Hepatology 49, 1166-1175 (2009).

\section{Acknowledgements}

We thank Zhiguo Zhang for retroviral plasmids expressing WT or mutant histone H3.1 or H3.3, Binbin Lai and Weiqun Peng for help with bioinformatics analysis, Hui Sun and Min Chen for in vivo insulin signaling assay, Yinyan Ma for the serum and tissue chemistries experiments, Victoria Noe-Kim for proofreading, and Chaochen Wang for scientific discussions and NIDDK Genomics Core for sequencing This work was supported by the Intramural Research Program of the NIDDK, NIH to K.G. 


\section{Author contributions}

Experiments were designed by L.Z., O.G., and K.G. Experiments were performed by L.Z., Y.J., Y.-K.P., J.-E.L., S.J., E.F., A.B., C.L., and O.G. Data were interpreted by L.Z., O.G., and K.G. The paper was written by L.Z. and K.G.

\section{Additional information}

Supplementary Information accompanies this paper at https://doi.org/10.1038/s41467018-04127-6.

Competing interests: The authors declare no competing interests.

Reprints and permission information is available online at http://npg.nature.com/ reprintsandpermissions/

Publisher's note: Springer Nature remains neutral with regard to jurisdictional claims in published maps and institutional affiliations. (c) (i) Open Access This article is licensed under a Creative Commons Attribution 4.0 International License, which permits use, sharing, adaptation, distribution and reproduction in any medium or format, as long as you give appropriate credit to the original author(s) and the source, provide a link to the Creative Commons license, and indicate if changes were made. The images or other third party material in this article are included in the article's Creative Commons license, unless indicated otherwise in a credit line to the material. If material is not included in the article's Creative Commons license and your intended use is not permitted by statutory regulation or exceeds the permitted use, you will need to obtain permission directly from the copyright holder. To view a copy of this license, visit http://creativecommons.org/ licenses/by/4.0/.

(C) The Author(s) 2018 